\title{
Long- and short-term triggering and modulation of mud volcano eruptions by earthquakes
}

\author{
Marco Bonini ${ }^{1, *}$ \\ ${ }^{1}$ Consiglio Nazionale delle Ricerche, Istituto di Geoscienze e Georisorse, Via G. La Pira 4, 50121 Florence, Italy \\ *corresponding author's contact information: Emals: mbonini@geo.unifi.it; mbonini@igg.cnr.it; Tel: +39 055 2757541;
}

Fax: 055290312

\author{
Maxwell L. Rudolph ${ }^{2}$ \\ ${ }^{2}$ Department of Geology, Portland State University, Portland, OR 97201, USA \\ Michael Manga ${ }^{3}$ \\ ${ }^{3}$ Department of Earth and Planetary Science, University of California, Berkeley, CA 94720, USA
}

(C) 2016. This manuscript version is made available under the Elsevier user license http://www.elsevier.com/open-access/userlicense/1.0/ 


\section{Abstract}

Earthquakes can trigger the eruption of mud. We use eruptions in Azerbaijan, Italy, Romania, Japan, Andaman Islands, Pakistan, Taiwan, Indonesia, and California to probe the nature of stress changes that induce new eruptions and modulate ongoing eruptions. Dynamic stresses produced by earthquakes are usually inferred to be the dominant triggering mechanism; however static stress changes acting on the feeder systems of mud volcanoes may also play a role. In Azerbaijan, eruptions within 2-10 fault lengths from the epicenter are favored in the year following earthquakes where the static stress changes cause compression of the mud source and unclamp feeder dikes. In Romania, Taiwan, and some Italian sites, increased activity is also favored where the static stress changes act to unclamp feeder dikes, but responses occur within days. The eruption in the Andaman Islands, and those of the Niikappu mud volcanoes, Japan are better correlated with amplitude of dynamic stresses produced by seismic waves. Similarly, a new island that emerged off the coast of Pakistan in 2013 was likely triggered by dynamic stresses, enhanced by directivity. At the southern end of the Salton Sea, California earthquakes increase the gas flux at small mud volcanoes. Responses are best correlated with dynamic stresses. The comparison of responses in these nine settings indicates that dynamic stresses are most often correlated with triggering, although permanent stress changes as small as, and possibly smaller than, 0.1 bar may be sufficient to also influence eruptions. Unclamping stresses with magnitude similar to Earth tides (0.01 bar) persist over time and may play a role in triggering delayed responses. Unclamping stresses may be important contributors to short-term triggering only if they exceed 0.1-1 bar.

\section{Introduction and aims of the work}

\subsection{Mud volcanoes: characteristics, processes and hazards}

The mobilization of deeply buried sediments and the extrusion of mud-breccias, saline water, and gases is a process known as mud or sedimentary volcanism. This process is driven by the presence of 
overpressured gases in the subsurface (Brown, 1990; Kioka et al., 2015), and is often linked to hydrocarbon traps at depth (Higgins and Saunders, 1974). Methane typically comprises the dominant fraction of released gases, though occasionally other gases (i.e., $\mathrm{CO}_{2}$ and $\mathrm{N}_{2}$ ) may prevail (Kopf, 2002). Eruption creates various forms of mud volcanoes, the most distinctive of which are the steep-sided extrusive conical edifices typically topped by a crater that extrudes mud flows, and bursting bubbles at the vent generate spatter (Fig. 1a-c), features that mimic in many ways the morphology of magmatic volcanoes (Fig. 1d, e). In addition, mud volcanoes share several other processes and properties with their igneous analogues, including (i) comparable internal structure (e.g., Stewart and Davies, 2006), (ii) a similar eruptive history (e.g., Evans et al., 2008; Kopf, 2008), (iii) buoyancy is often supplied by exsolved gases (Manga et al., 2009), and (iv) eruptions triggered by earthquakes have similar sensitivities to ground deformation (Wang and Manga, 2010). This suggests that, apart from obvious differences (i.e., the role of temperature and crystallization), some similar processes govern both igneous and mud volcanoes.

The dimension of the extrusive edifices is highly variable, ranging in size from the decimeter- to meter-scale (gryphons and mud cones) to large volcanoes up to a few hundred meters high and several kilometers across (Fig. 1a-d). Mud volcanoes are quiescent for most of their lifetimes, with occasional rhythmic, sometime vigorous, seepage of water, gas, and hydrocarbons, including the expulsion of gas bubbles from muddy waters (Fig. 1c). The analysis of gas geochemistry suggests that the plumbing system of dormant mud volcanoes is continuously recharged from deep-seated reservoirs through a system of branched conduits (Mazzini et al., 2009). However, mud volcanoes may experience episodic paroxysmal eruptive phases that involve the violent ejection of mud breccias and mud flows from a summit crater. The eruption rates and temperatures are significantly lower than those of magmatic volcanoes, and thus the hazard mud volcanoes pose is primarily local (e.g., Etiope, 2015). There are however remarkable exceptions. During violent eruptions, subaerial mud volcanoes can discharge up to 
500 million $\mathrm{m}^{3}$ of flammable methane in a few hours (Kopf, 2002). Self-ignition can produce large explosive flaming eruptions leading to loss of life at some Azerbaijan mud volcanoes (Guliyev and Feyzullayev, 1997) (Fig. 1f, g).

\subsection{Mud volcano eruptions and earthquakes}

We can probe processes that govern the initiation of eruptions by studying the response of mud volcanoes to known external forcing such as stresses produced by earthquakes. Eruptions within hours to days of an earthquake are generally assumed to be the most convincing examples of triggered eruptions (Manga and Brodsky, 2006), as delayed triggering is more difficult to assess (Selva et al., 2004). The number of documented magmatic eruptions triggered by earthquakes is small (Linde and Sacks, 1998; Watt et al., 2009), though there is growing evidence that there may be widespread and even global increases in volcanic activity following large earthquakes (e.g., Madonia et al., 2013; Delle Donne et al., 2010; Eggert and Walter, 2009; Tsunogai et al., 2012; Kusumoto et al., 2015; Lupi et al., 2016).

The first step in understanding why earthquakes influence eruptions is to identify the responsible stress. The static stresses created by fault slip decay with distance $R$ from the epicenter as $1 / R^{3}$, and become negligible within a few fault lengths from epicenter. Static stress changes are permanent, and have the ability to create stress shadows that may retard earthquakes on nearby faults and shut down aftershocks (Harris and Simpson, 1996; Stein, 1999; Toda et al., 2012). Static stress changes may initiate eruptions by expanding (e.g., Barrientos, 1994; La Femina et al., 2004; Diez et al., 2005; Walter and Amelung, 2007; Fujita et al., 2013) or compressing (e.g., Feuillet et al., 2011) magma reservoirs, or unclamping magma ascent paths (Nostro et al., 1998; Bursik et al., 2003; Walter, 2007; Bonali, 2013; Bonali et al., 2013). The dynamic stress changes produced by passing seismic waves are larger than static stress changes, decaying as $1 / R^{1.66}$, and thus may influence the subsurface to distances of many 
fault lengths from the epicenter (Kilb et al., 2000). Unlike static stress changes, the passage of seismic waves should not produce permanent changes in stress unless they alter the mechanical or transport properties of the crust. Dynamic stresses may influence eruptions by changing permeability (Walter et al., 2009; Manga et al., 2012), nucleating or mobilizing bubbles (Cannata et al., 2010; Crews and Cooper, 2014), or mobilizing magma (Hill et al., 2002; Sumita and Manga, 2008). It is generally concluded that near-field triggering of eruptions, within a couple fault lengths of the epicenter, results from some combination of static and dynamic stress changes, while dynamic stress changes appear more appropriate to explain far-field triggering (e.g., Hill et al., 2002; Steacy et al., 2005; Manga and Brodsky, 2006; Walter et al., 2007). The role of static stress changes may perhaps be more straightforward to assess over long time scales, well after the passage of seismic waves.

Studies of seismic sequences indicate that aftershocks can be promoted or suppressed by stress changes of just \pm 0.1 bar $(10 \mathrm{kPa})$, with delays in the response that may vary from seconds to decades (e.g., Reasenberg and Simpson, 1992; King et al., 1994; Stein, 1999). In volcanic systems, the critical threshold of stress change for influencing eruptions is not well defined. Some studies suggest that eruptions may be potentially triggered by static stress changes as small as 0.1-1 bar (Bautista et al., 1996; Nostro et al., 1998). A similar limit has also been suggested for the internal pressure fluctuations caused by dynamic changes (e.g., Walter et al., 2007). In some cases even very small stresses resulting from solid Earth tides ( 0.01 bar) appear to influence these systems (e.g., Tanaka et al., 2004; Rubinstein et al., 2008; Gallego et al., 2013). As with mud volcanoes there are no well-defined thresholds of stress change for the triggering of eruptions, though both mud and igneous volcanoes earthquake-triggered eruptions show similar sensitivities to ground deformation (Wang and Manga, 2010).

In some areas, mud volcanoes display an exceptional density, and may provide closely-spaced stress receptors. We therefore analyze these mud volcanoes to decipher the time-space reaction of these 
systems to static and dynamic stress changes, particularly the effect on (i) delayed and (ii) immediate responses of mud volcanoes, as well as (iii) in modulating ongoing eruptions. In particular, we consider 9 settings where some combination of a large number of earthquakes and mud volcanoes permit such analyses. We undertake the present compilation of observations, and analysis because the number of examples of triggered eruptions is more than double that in the most recent review (Manga et al., 2009) and, more importantly, over the past few years a better understanding of eruption processes and structural controls allows us to perform a more quantitative analysis of the geological record.

\section{Structural controls on plumbing systems of mud volcanoes}

Mud volcanoes have been usually considered the surface expression of intrusive shale diapirs, which are subsurface overpressured muddy masses driven upward by buoyancy forces resulting from the density contrast with the denser overburden (Brown, 1990; Morley and Guerin, 1996; Kopf, 2002). Other models suggest that mud volcanoes are fed from deep overpressured fluid-rich source layers, and the ascent of mud-water-gas mixtures occur through a complex network of conduits, pipes and faultcontrolled planar pathways that may connect variably-sized fluid reservoirs of undercompacted mud, which likely consist of dense networks of mud-filled fractures intruding the country rock (e.g., Cooper, 2001; Kopf, 2002; Kopf et al., 2003; Morley, 2003; Stewart and Davies, 2006; Davies et al., 2007, 2013; Bonini, 2008; Roberts et al., 2010). In mud volcanoes, extensive fluid flow can extend vertically for $>1$ km (e.g., Sobissevitch et al., 2008; Davies et al., 2013; Kioka et al., 2015).

Field observations of exposed fossil feeder systems and seismic data indicate that vertical

migration of deep fluids may occur along sub-circular pipes and conduits (Roberts et al., 2010), and through long and narrow steep mud-filled planar fractures similar to dikes (Morley et al., 1998; Morley, 2003; Tingay et al., 2003; Cooper, 2001; Stewart and Davies, 2006). The steep mud-filled intrusions have been interpreted as hydraulic fractures (e.g., Morley et al., 1998; Morley, 2003) and hence as 
potential pathways for the transfer of subsurface material and fluids to the surface (Davies et al., 2007, 2013). We use herein the term 'feeder dike' to indicate subsurface zones containing planar structures, including sets of fractures, faults and hydraulic fractures that provide the pathways for the ascent of mud. The common presence of aligned vents and elongated mud volcano edifices is consistent with eruption along steep sub-planar surfaces that act as feeder dikes (Bonini, 2012) (Fig. 1c).

In general, the orientation of subsurface dikes can be inferred from the geometrical characteristics of the mud volcano edifices. In particular, the long axis of large, elongated mud volcanoes and the direction of aligned vents approximate the orientation of the underlying feeder dike. This relationship was established for magmatic volcanoes (Nakamura, 1977), and has been later proposed for mud volcano systems (Bonini, 2012). The identification of feeder dikes beneath elongated mud calderas is more complex because these may trend parallel to either the long or the short caldera axis (for details see Bonini, 2012).

Nostro et al. (1998) proposed that static stress changes caused by earthquakes promoted eruptions at Vesuvius (southern Italy) by compressing a sub-spherical magma chamber at depth, and opening suitably-oriented dikes at more shallow depths. We thus evaluate whether similar conditions also characterized mud volcanoes, whose plumbing systems have some similarities to magmatic volcanoes (see discussion in Stewart and Davies, 2006 and Evans et al., 2008).

\section{Methods}

We compute static stress changes caused by an earthquake on potential feeder dikes at each mud volcano system. We calculate the normal stress change $\left(\Delta \sigma_{\mathrm{n}}\right)$, positive if the fault is unclamped, and shear stress change $(\Delta \tau)$, positive in the direction of fault slip. To determine whether the static stress changes promote slip, we also calculate the Coulomb Failure Function (e.g., Reasenberg and Simpson, 
1992; Stein et al., 1992; Harris, 1998; Stein, 1999; King et al., 1994; Cocco and Rice, 2002; Kilb et al., 2002; King, 2014), $\triangle \mathrm{CFF}$,

$$
\Delta \mathrm{CFF}=\Delta \tau+\mu\left(\Delta \sigma_{\mathrm{n}}+\Delta P\right)
$$

where $\Delta \tau$ is the shear stress change on the fault (positive in the direction of fault slip), $\Delta \sigma_{\mathrm{n}}$ is the normal stress change (positive if the fault is unclamped), $\mu$ is the friction coefficient, and $\Delta P$ is the change in pore pressure within the fault. The change in Coulomb failure stress is normally rewritten as:

$$
\Delta \mathrm{CFF}=\Delta \tau+\mu^{\prime} \Delta \sigma_{\mathrm{n}}
$$

where $\mu^{\prime}$ is the apparent coefficient of friction that includes the contribution of the fluid pressure change and the material properties of the fault zone. In particular, the friction and Skempton coefficient can influence the computation of stress changes, but not in a substantial way providing that these vary within a realistic interval (Cocco and Rice 2002; Chan and Stein, 2009). Stresses are computed in a homogeneous elastic half-space (Okada, 1992). The assumption of an elastic medium is an approximation to the real Earth that is usually invoked when studying the response of magmatic volcanoes to earthquakes (e.g., Bautista et al., 1996; Nostro et al., 1998; Walter, 2007), and we extend this assumption to the study of mud volcanoes based on the concept that mud and magmatic volcano systems share some causal mechanisms and properties, and are governed by similar processes (see section 1.1). We adopt uniform values for elastic moduli (based on King et al., 1994; Freed and Lin, 2001; Lin and Stein, 2004; Toda et al., 2005, 2011; Lin et al., 2011): Poisson's ratio v=0.25, Young's modulus $E=8 \times 10^{5}$ bar ( $\left.80 \mathrm{GPa}\right)$, implying shear modulus, $G=3.2 \times 10^{5}$ bar $(32 \mathrm{GPa})$. For simplicity we have assumed the same Young's modulus and Poisson's ratio for all the considered study cases; lower or higher values of Young's modulus would reduce or increase the magnitude of the stress changes, respectively. Natural systems are likely characterized by heterogeneities and zones of weakness. However, we lack detailed information about subsurface structure and material properties, and assume 
homogenous elastic properties. We assumed an apparent coefficient of friction, $\mu^{\prime}=0.4$, which is the average of the 0.0-0.8 range of possible values (King et al., 1994). The shear and normal stresses produced by a 'source' earthquake can be resolved onto specific 'receiver' faults or dikes. The receiver faults are defined by their strike, dip, and rake, but rake does not influence the normal stress change.

The calculations of normal stress changes on feeder dikes $\left(\Delta \sigma_{\mathrm{n}}\right.$; either clamping or unclamping) were carried out using Coulomb 3.3 (http://www.coulombstress.org; Toda et al., 2011). We used published source fault models or we determined the source earthquake fault using the empirical fault geometry from Wells and Coppersmith (1994) and used the reported hypocenter as the fault center.

Although the models are based on available geologic and geophysical data, a number of assumptions and simplifications are necessarily introduced. Our results may be affected by uncertainties in hypocentral and epicentral location, as well as by the geometry of the causative fault (i.e., rake, dip or strike). For this reason, when possible we have considered a range of focal mechanisms in the computations. Another crucial feature of the calculation is the orientation of potential feeder dikes. We have deliberately assumed the feeder dikes to be vertical (dike top assumed at $0.01 \mathrm{~km}$ depth) because we lack information to constrain their subsurface geometry. Given these uncertainties, we have usually calculated normal stress changes at a depth of $1 \mathrm{~km}$, which represents a minimum estimate of vertical fluid transmission that in mud volcanoes can extend vertically for $>1$ km (e.g., Davies et al., 2013). Sensitivity tests show that the magnitude of normal stress changes acting on the feeder dike is virtually insensitive to $\mu^{\prime}$, while there is some sensitivity to its dip. This implies that a better knowledge of the mud volcano plumbing system would allow a more accurate estimation of the stress changes. 
In the following sections we examine a number of worldwide mud volcanoes that reacted to earthquakes. The mud volcanoes are representative of different settings and regions, and have been selected on the basis of their immediate or delayed response, their behavior during different earthquakes distributed over short and long time spans, or other peculiarities related to the structural setting of the mud volcano. We begin by summarizing the responses of mud volcanoes in each setting and the relationship between the responses and the stress changes produced by the earthquakes. We then use these observations to assess, to the extent possible given a finite number of observations, the controls on short-term and long-term triggering, and the relative roles of static and dynamic stresses.

\section{Short-term response of mud volcano systems to earthquakes}

\subsection{Mud volcano response to the intermediate depth 1977 Vrancea earthquake (Romania)}

Mud volcano systems occur along the compressive external margin of the arcuate Carpathian fold-and-thrust belt (Baciu et al., 2007) (Fig. 2a). The southeastern part of the Carpathian arc (Vrancea region) is characterized by very clustered, persistent and strong intermediate-depth seismic activity (mostly in the $\sim 70-170 \mathrm{~km}$ depth range) with large moment release ( $\mathrm{Mw}=6.9$ to 7.7 ) (Oncescu and Bonjer, 1997). This seismicity may be generated by contact between the subducting subvertical Vrancea mantle slab and the detached mantle of the upper plate, and partly from failure internal to the downgoing lower plate (Vrancea mantle slab) due to its vertical stretching (Cloetingh et al., 2004). This region also hosts the most impressive mud volcanoes of Romania, which are located approximately along the axis of the $20 \mathrm{~km}$-long Berca-Arbanasi hydrocarbon-bearing anticline (Baciu et al., 2007)

(Fig. 2b). Paclele Mari and Paclele Mici are the largest mud volcanoes. There, active seepage occurs above truncated cone-shaped, kilometre-scale hills, which are elongated in a $\sim \mathrm{N}-\mathrm{NNE}$ direction and presumably represent larger mud volcano edifices. In both mud volcano fields, the zone of active seepage occurs within an elliptical region that is elongated in the same direction as the main volcanic 
edifice. Gryphons and $<10$ m-tall mud cones define $\sim N 08^{\circ}$ E-trending alignments (Fig. 2c) subparallel to the long axis of both the main edifice and elliptical seepage area, a setting that may be structurally controlled by fractures and folds parallel to the fold axis (e.g., Fig. 6a in Bonini, 2012).

The Mw7.4 Vrancea earthquake hit this region on 04 March 1977. The focal mechanism reveals that the earthquake was a thrust event with focal depth of around $90 \mathrm{~km}$ (e.g., Oncescu and Bonjer, 1997) (Fig. 2a). This earthquake produced new vents and extinguished others due to the reactivation of the main longitudinal faults, and triggered an eruption lasting for 6 hours at the Beciu mud volcano (Baciu and Etiope, 2005). The mud volcanoes lie in the near-field as they are located approximately half of one fault length away from the epicenter (Table S1). We used both the CMT solution and the source model of Ganas et al. (2010) to compute the Coulomb stress changes produced by the 1977 Vrancea earthquake (Table S1). Both source models give comparable results in that both predict volumetric expansion and unclamping normal stress changes (in the range $\sim 0.2-0.8$ bar) on vertical N08 ${ }^{\circ}$-trending receiver dikes, representative of the trend of vent alignments in the area (Fig. 2d, e and Table S1). The computed normal stress change exceeds the conventional triggering threshold, and thus the short-term response of these mud volcanoes to the Vrangea earthquake may thus have resulted from some combination of dynamic stresses and normal stress changes unclamping the feeder dike.

\subsection{The 2004 Great Sumatra earthquake and the mud volcano eruption at Baratang (Andaman-}

\section{Nicobar Islands)}

A number of mud volcanoes occur on Baratang Island, in the Andaman-Nicobar Islands (Chaudhuri et al., 2012). One of them erupted, throwing mud above the height of neighboring trees, only several minutes after the Sumatra-Andaman (Mw=9.1; USGS report; http://earthquake.usgs.gov) main shock of 26 December 2004 (Mellors et al., 2007, and references therein) (Fig. 3a). Owing to the timing, this earthquake-eruption pair is considered a reliable instance of short-term seismic triggering 
(Mellors et al., 2007). The same mud volcano experienced eruptions in 2003 and 1983. The eruption of 18 February 2003 formed a mud mound about $30 \mathrm{~m}$ in diameter and $2 \mathrm{~m}$ tall at its center. Two N20 ${ }^{\circ} \mathrm{E}-$ oriented parallel fractures formed across the edifice; the larger was $15 \mathrm{~m}$ long, $30 \mathrm{~cm}$ wide, with fluid oozing from its center (Geological Survey of India, 2003). The trend of the open fractures was subparallel to the ca. $\mathrm{N} 25^{\circ} \mathrm{E}$ elongation of the main extrusive edifice, which may represent the orientation of a subsurface feeder dike.

We assume a 450-patch finite-source rupture model (downloaded at http://www.seismo.ethz.ch/static/srcmod/Homepage.html; Ammon et al., 2005), with Mw=9, fault strike $=320^{\circ} \mathrm{E}, \operatorname{dip}=15^{\circ}$, length $=450 \mathrm{~km}$, width $=180 \mathrm{~km}$, and rake $=91.7$, and we calculate the normal stress changes on a vertical feeder dike with a strike of $\mathrm{N} 25^{\circ} \mathrm{E}$. Despite being more than $1000 \mathrm{~km}$ away from the epicenter, the $\mathrm{Mw}=9$ earthquake was able to produce unclamping stresses on a receiver dike striking $\mathrm{N} 25^{\circ} \mathrm{E}$ and subtle volumetric expansion (Fig. 3c; Table S2). The Great Sumatra earthquake also triggered numerous seismic events with $\mathrm{M} \geq 5$ within a radius of $50 \mathrm{~km}$ from the mud volcano (USGS report; http://earthquake.usgs.gov; Fig. 3b). The timing of the eruption is however somewhat uncertain (it is reported to have occurred several minutes after the earthquake; Mellors et al., 2007), and thus triggering by local aftershocks cannot be ruled out. The computed normal stress changes are less than the magnitude of tidal stresses, and thus the contribution of unclamping stresses in the shortterm triggering is likely to be insignificant in comparison to the effect of dynamic stresses.

\subsection{When faults controlling mud volcano systems rupture: The Chihshang Fault and the short-term} mud volcano response to the 2003 Chengkung earthquake (Taiwan)

Numerous mud volcanoes occur in Taiwan, an exposed arc-continent collision belt developed at the boundary between the Philippine Sea Plate and the Eurasian Plate (e.g., You et al., 2004) (Fig. 4). The NNE-trending Longitudinal Valley, in proximity of the eastern coast of Taiwan, marks the suture 
zone between the two plates. There, a regional $\sim$ E-dipping high-angle active thrust, referred to as Longitudinal Valley Fault (LVF), superposes with dominant thrust kinematics and minor component of left-lateral slip the remnants of a westward-facing Neogene island arc (i.e., the Coastal Range) over the Central Range (e.g., Tsai, 1986; Angelier et al., 2000; Ching et al., 2007) (Fig. 4a). The E-dipping Chihshang Fault is the main LVF segment in the South. The Chihshang Fault has a listric geometry and ruptured on 10 December 2003 producing the Mw6.8 Chengkung earthquake (e.g., Kuochen et al., 2007; Mozziconacci et al., 2009) (Fig. 4b).

Mud volcanoes occur both on the hanging wall and around the surface trace of the Chihshang Fault (Sung et al., 2010; Jiang et al., 2011) (Fig. 4a, b), and lie in the near-field of the Chengkung earthquake, the epicentral distance of mud volcanoes being invariably less than one fault length. The mud volcanoes are thus intimately associated with the Chihshang Fault, whose deformation zone is expected to control their deep plumbing systems (i.e., fluid pathways and reservoirs). It was reported that the Chenkung earthquake influenced the activity of two of these mud volcanoes, the Luoshan and Leikunghuo mud volcanoes (Jiang et al., 2011) (Fig. 4a). Local witnesses report that the Luoshan mud volcano erupted with strong noise nearly synchronously with the main shock, spewing mud, gas and water and formed a large mud basin. No inhabitants could observe the coseismic behavior of the Leikunghuo mud volcano to the south, but later inspection documented that the seismic event produced two sets of fresh faults or fractures (oriented $\mathrm{N} 16^{\circ} \mathrm{E}$ and $\mathrm{N} 85^{\circ} \mathrm{E}$ ) crosscutting the volcano edifice and oozing muddy waters (Jiang et al., 2011).

Different focal mechanisms and source models have been published, which imply different fault geometry (USGS; Centroid Moment Tensor solutions catalog; Wu et al., 2006; Kouchen et al., 2007; Mozziconacci et al., 2009). We computed the normal stress changes for the different solutions, on vertical feeder dikes with strike of $\mathrm{N} 16^{\circ} \mathrm{E}$ and $\mathrm{N} 85^{\circ} \mathrm{E}$, which is the mean trend of fractures observed at the Leikunghuo mud volcano (Table S3). Given the proximity of the mud volcanoes to the epicenter, 
the calculated normal stress changes are relatively large, with values that often fall in the range 1-3 bar (Table S3). In a few cases the stress changes may be unrealistically high, because of stress concentration at the edges of the rupture, e.g, the USGS solution (Table S3).

In general, the computed normal stress changes are highly sensitive to the different source models (see Table S3). For instance the Kouchen et al. (2007) source fault strikes oblique to the N20 ${ }^{\circ}$ trending Chihshang Fault, and this implies that the feeder dikes at Leikunghuo and Luoshan mud volcanoes would have been unclamped and clamped, respectively, by the Chenkung earthquake (Table S3). Other joint inversions of geodetic and seismological data yield causative earthquake faults oriented sub-parallel to the Chihshang Fault (Wu et al., 2006; Mozziconacci et al., 2009) (cf. Fig. 4a and Table S3). In particular, the source models of Wu et al. (2006) and Mozziconacci et al. (2009) give equivalent results in that both models predict volumetric expansion and relatively large unclamping stresses at both Luoshan and Leikunghuo mud volcanoes (Fig. 4c, d; Table S3). If we base our considerations on these source models, the computed normal stress changes generally tend to unclamp the feeder dikes (apart from the Luoshan mud volcano in the model by Kouchen et al. 2007), and the unclamping stress changes generally exceed 1 bar. Unclamping of the feeder dike may have thus contributed to the shortterm response of these mud volcanoes, which lie in the near-field of a causative earthquake fault that is also structurally controlling the mud volcanoes.

4.4. Birth of an island (Makran accretionary wedge) shortly after the 2013 Balochistan earthquake (Pakistan)

A number of mud volcanoes are exposed in the Makran accretionary wedge, and also in the submerged part of the wedge (Snead, 1964; Delisle et al., 2002; Schlüter et al., 2002) (Fig. 5a). In coastal Makran, trains of E-W trending, south-verging thrust-related folds and thrusts affect the 
Miocene to Pleistocene sediments, and the mud volcanoes almost invariably occur over the crest of these anticlines (e.g., Snead, 1964; Delisle et al., 2002; Burg et al., 2008).

A Mw7.7 earthquake struck the Balochistan province in south-central Pakistan on September 24, 2013. The earthquake occurred at shallow depth $(15 \mathrm{~km})$, and resulted from left-lateral oblique-strikeslip movements along the southern part of the active Chaman Fault (USGS report; http://earthquake.usgs.gov; Fig.5a). A few hours after the earthquake a new small island about $200 \mathrm{~m}$ across and $20 \mathrm{~m}$ high emerged off the Gwadar coast, $383 \mathrm{~km}$ from the epicenter (Fig.5b). Reports show that the island had a blocky surface containing seafloor species and fish, and mud breccias and methane were emitted at the center and apex of the island in the days after its appearance. Emergence of mud volcanoes on the shallow shelf is common and may also occur after earthquakes (Kassi et al., 2013). Three mud islands emerged in the Arabian Sea off the coast of Makran after the November 27, 1945 M8.0 earthquake (Sondhi, 1947). One of these is Malan Island, which emerged three times at the same spot, in November 1945, March 1999 and November 2010 (Kassi et al., 2013) (Fig.5a). However, the attribution of the new island to a mud volcano is not unequivocal. There is the possibility that the island developed as a bulge of the seafloor driven by the sudden release of deep gas hydrates, a process that has been described in the area (Fisher et al., 2013), or as a sub-circular massive vertical uplift caused by the intrusion of subsurface mud plugs, a phenomenon described in the Barbados accretionary prism (Deville et al., 2006). We favor a mud volcano origin because of the mud breccia texture of the surface.

We evaluate the hypothesis that the island was a mud volcano and calculate the change in normal stress on potential dikes that sourced the mud volcano. In the region, potential feeder dikes are generally oriented between $\mathrm{N} 20^{\circ} \mathrm{E}$ and $\mathrm{N} 30^{\circ} \mathrm{E}$. In particular, the ca. $25 \mathrm{~m}$ tall Tang mud volcano elongates $\mathrm{N} 20^{\circ} \mathrm{E}\left(\mathrm{Fig} .5 \mathrm{c}\right.$ ), and in the Ormara field the rows of vents are aligned ca. $\mathrm{N} 27^{\circ} \mathrm{E}$ and the nearby mud volcano elongates in a $\mathrm{N} 25^{\circ} \mathrm{E}$ direction (Bonini, 2012) (Fig.5d). We assume the 7-patch fault model reported in Avouac et al. (2014). The Mw7.7 earthquake produced unclamping stresses on 
a receiver dike striking $\mathrm{N} 25^{\circ} \mathrm{E}$ (Fig.5e; Table $\mathrm{S} 4$ ). However, the island shows a subtle but clear symmetrical elongation in a $\mathrm{N} 122^{\circ} \mathrm{E}$ direction (Fig.5b). A local feeder dike with the latter orientation would have been clamped (Fig.5f). If dikes trend parallel to the crest of anticlines (N90 $\left.{ }^{\circ} \mathrm{E}\right)$ dikes are also clamped (Table S4). We thus favor the hypothesis that dynamic stress changes are the dominant earthquake triggering mechanism at the new - either mud volcano or seafloor bulge - island because it lies close to a nodal plane (Fig.5e,f), rupture was unilateral towards the southwest, and the southwestern-most extent of the rupture just $220 \mathrm{~km}$ from the new island (Avouac et al., 2014). Thus, fault geometry and directivity effects would have further enhanced the amplitude of dynamic stresses from the seismic waves.

\subsection{Mud volcano response to the 2012 Emilia seismic sequence (northern Italy)}

In the Northern Apennines, most mud volcanoes occur over the hanging wall of the SSW-dipping active Pede-Apennine thrust system that borders, to the southwest, the topographically flat Po Plain (e.g., Bonini, 2012) (Fig.6a, b). Active thrusts are also buried in the Po Plain beneath a thick sequence of Late Miocene-Quaternary clastic deposits (Boccaletti et al., 2004).

A relatively strong seismic sequence nucleated on $\sim$ SSW-dipping blind thrust faults forming the buried compressive front of the Northern Apennines fold-and-thrust belt (INGV, TDMT; http://cnt.rm.ingv.it/tdmt.html) (Pondrelli et al., 2012; Saraò and Peruzza, 2012; Govoni et al., 2014). The sequence started with the Mw4.3 earthquake of 19 May 2012, shortly followed by the Mw6.1 main shock of 20 May 2012 with epicenter in the Finale Emilia area (Fig.6a). On 29 May 2012, another strong earthquake of Mw5.9 struck the region near Mirandola, southwest of the 20 May epicenter (Fig.6a). Different interpretations of specific seismogenic structures have been proposed depending on the assumed focal depth of earthquakes (e.g., Anzidei et al., 2012; Govoni et al., 2014). The setting illustrated in the crustal section of Fig. $6 \mathrm{~b}$ assumes that the main seismic events of 20 May were 
generated on a $\sim$ SSW-dipping thrust ramp, and those of 29 May occurred mainly on the gently-dipping basal detachment and secondarily on the thrust ramp lifting the Mirandola anticline.

Historical chronicles report that the Pede-Apennine mud volcanoes experienced several large eruptions, some of which were likely triggered by earthquakes (Bonini, 2009). None of the mud volcanoes experienced large eruptions after the main seismic events, yet inspection of these features a few days after the 20 and 29 May 2012 main shock revealed that the majority of them clearly increased their activity above the background conditions observed a few weeks before the earthquakes. We could not measure the pre- and post-seismic gas flux, and therefore the observed characteristics of increased activity are necessarily described qualitatively in Table S5. On later visits (March and August 2013), the mud volcanoes were found to be in a state of near-quiescence, with very little net mud extrusion, with the eruption dominated by gas emission by bursting bubbles.

We calculated static stress changes created by the main Emilia earthquakes to assess the potential effects on mud volcano activity. A previous analysis concluded that mud volcanoes with increased activity were invariably situated in regions characterized by unclamping stresses on assumed $\mathrm{N} 10^{\circ} \mathrm{E}-$ trending feeder mud dikes (Manga and Bonini, 2012). Here we present an improved analysis using the fault parameters that resulted from the inversion of the SAR dataset (Bignami et al., 2012), revised focal mechanism solutions (Saraò and Peruzza, 2012) (Table S6) and additional observations. Practically all the mud volcanoes that responded to the 20 May earthquake lie in the unclamping region created by this event, where the applied stress would act to open the feeder dikes that in turn would encourage fluid discharge (Fig.6c; Table S5). The magnitude of these stress changes is generally slightly above that of tidal stresses (Table S5). The normal stress changes are greatest at CasolaQuerzola and Regnano mud volcanoes (0.023-0.026 bar), which had unambiguous enhanced activity (Table S5). A similar normal stress change pattern results from the 29 May event. The great majority of mud volcanoes occur again in the region with unclamping stresses, whereas only Puianello lies in an 
area of clamping stresses that would discourage fluid discharge by closing the feeder dikes (Fig. 6d; Table S5). Reduced activity was indeed noted at Puianello after this seismic event, whereas abnormally increased activity was observed at many of the other mud volcanoes (Table S5). The results of volumetric strain calculations indicate that all of the mud volcanoes fall in the dilatation field created by both earthquakes of 20 and 29 May (volumetric strain range $5 \times 10^{-8}$ to $10^{-9}$ ).

\subsection{Response of the LUSI mud eruption (East Java, Indonesia) to multiple earthquakes}

The LUSI mud eruption, near Sidoarjo, East Java, Indonesia is the largest (by erupted volume) and longest-lasting continuous mud eruption in history (Fig. 7a). Because the eruption began just two days after the Mw 6.3 Yogyakarta earthquake of 26 May 2006, which occurred at an epicentral distance of $255 \mathrm{~km}$ (per the USGS catalog), there was considerable debate as to whether the eruption was triggered by the earthquake (Fig. 7b). An alternative hypothesis was that drilling operations at a nearby gas exploration well, which left a $\sim 1700 \mathrm{~m}$ uncased section through the overpressured, undercompacted Upper Kalibeng Formation (the source of the erupting solids), were the primary cause of the eruption. For a thorough discussion of the cause for the LUSI mud eruption, we refer the interested reader to earlier papers that outline the key arguments for (Mazzini et al., 2007; Istadi et al., 2009; Lupi et al., 2013) and against (Manga, 2007; Davies et al., 2008; Tingay et al., 2008, 2015; Rudolph et al., 2015) an earthquake trigger.

Mazzini et al. (2007) suggested that the ongoing eruption at LUSI was affected by earthquakes on 6 and 8 September (local dates), 2006. The discharge from LUSI had been gradually waning, with cyclic/episodic discharge, from 10 August to 10 September, 2006. Within several days of the two earthquakes, which had magnitudes Mb 4.3 and 3.9 and epicentral distances of 114 and $268 \mathrm{~km}$,

discharge reportedly increased to $160,000 \mathrm{~m}^{3} /$ day (Mazzini et al., 2007, Figure 5). The maximum discharge reported at LUSI, $180,000 \mathrm{~m}^{3} /$ day occurred in late September 2006 , shortly after a swarm of 
earthquakes between 20-21 September with magnitudes Mb ranging from 3.7-4.6 and epicentral distances of 268-296 km from LUSI (magnitudes and locations are taken from the USGS catalog). A magnitude 7.4 earthquake on 8 August, 2007 and a magnitude 8.4 earthquake on 12 September 2007 are also reported to have caused discharge to increase (Davies et al., 2008). The Mw5.4 Java earthquake of 26 April 2011 caused the eruption at LUSI to transition to two centers rather than one, approximately one hour after the event and one of the levees containing erupted mud at LUSI failed $\sim 5 \mathrm{~h}$ after the earthquake (Mazzini et al., 2012).

Efforts to understand the modulation of activity at LUSI by earthquakes are hampered by the discontinuous record of eruptive activity as well as the lack of availability of information about local earthquakes. Continuous records of eruptive activity at LUSI are not available for most periods of time, and the methods used to obtain many published discharge estimates are often not thoroughly described. Due to the sparsity of seismometers in East Java, moment tensor solutions are not available for the majority of earthquakes that may have affected the ongoing eruption at LUSI. For instance, of the earthquakes shown in Figure 5 of Mazzini et al. (2007), only the Yogyakarta earthquake of 27 May 2006 has a published moment tensor solution. Without moment tensors, static stress changes at LUSI cannot be calculated. However, moment tensors are available for some events that reportedly affected the eruption in 2007 and 2011 as well as one additional event in 2007 that we show to have produced static stress changes, volumetric strains, and ground motion amplitudes comparable to the events that did affect the eruption.

We calculated static stress changes resolved on a vertical feeder dike beneath the LUSI eruption with orientation parallel to the left-lateral Watukosek fault $\left(\mathrm{N} 35^{\circ} \mathrm{E}\right)$ (Mazzini et al., 2009), whose orientation is similar to that of the lineament of vents at which the eruption began (Istadi et al., 2009). We calculate the volumetric strain at a depth of $1500 \mathrm{~m}$, comparable to the inferred source of erupting solids at LUSI (e.g., Mazzini et al., 2007; Istadi et al., 2009; Sawolo et al., 2009), and we calculate the 
unclamping stress on the feeder dike at a depth of $500 \mathrm{~m}$. Surface deformation data (Shirzaei et al. 2015) and gas geochemistry (Mazzini et al. 2012; Tingay et al. 2015) indicate that there is an additional source of fluids at depths greater than about $3 \mathrm{~km}$. We also calculated $\Delta C F F$ for the Watukosek fault at a depth of $500 \mathrm{~m}$, assuming left-lateral slip, and using the friction coefficient and elastic moduli listed in Section 3. The calculated static stress changes and volumetric strains are given in Table S7. Based on the results of these calculations, we cannot differentiate between events that affected the ongoing eruption and those that did not based on either the sign or amplitude of $\triangle \mathrm{CFF}$, unclamping stresses on feeder dikes, or volumetric strain. In particular, the two events of 8 August 2007 and 12 September 2007 produced opposite signs of volumetric strain, $\triangle \mathrm{CFF}$, and unclamping stresses, but both events are reported to have caused discharge to increase. This suggests that static stresses are not the dominant mechanism by which earthquakes affect the ongoing eruption at LUSI.

Estimates of seismic energy density (Wang, 2007), as well as peak ground acceleration, peak ground velocity, and arias intensity associated with the propagation of seismic waves can be calculated from published attenuation relationships specific to East Java (Davies et al., 2008). In Figure 7c we show discharge at LUSI along with estimated seismic energy density produced by earthquakes that occurred within $1500 \mathrm{~km}$ of LUSI (Mazzini et al. (2007) restricted their consideration to earthquakes occurring within $300 \mathrm{~km}$ of LUSI):

$$
\mathrm{M}=2.7+0.69 \log _{10} e+2.1 \log _{10} r
$$

where $\mathrm{M}$ is earthquake magnitude, $e$ is seismic energy density in $\mathrm{J} / \mathrm{m}^{3}$, and $r$ is epicentral distance in km. In Figure 7d, we calculated Peak Ground Velocity (PGV) using the empirical attenuation relationship derived specifically for East Java from Davies et al. (2008):

$$
\mathrm{PGV}=\exp (4.67+2.04 M-4.53 \ln r+0.00478 r)
$$

where PGV is given in $(\mathrm{m} / \mathrm{s})$. This record contains several earthquakes that produced ground motion as strong as or stronger than the Yogyakarta earthquake. In particular, the Mw 7.7 event of 17 July 2006 
(epicentral distance $625 \mathrm{~km}$ ) is expected to have produced stronger ground motion, twice the seismic energy density, and an order of magnitude larger PGV than the Yogyakarta earthquake. No change in eruptive behavior was noted at LUSI associated with this event, despite the large amplitude calculated for any of the proxies for the amplitude of dynamic stresses. Neither seismic energy density nor PGV as a metric for the intensity of seismic waves at LUSI yields a clear relationship between intensity of dynamic shear stress and changes in the rate of the ongoing eruption.

\section{Delayed response of mud volcanoes}

It is relatively straightforward to assess seismic trigging for mud volcanoes that have erupted within a few days of large earthquakes and that are located at suitable epicentral distances (e.g., Manga and Brodsky, 2006). The assessment of delayed triggering (i.e., eruptions that occur several days or months after a potentially triggering earthquake) is more challenging, in that it is often difficult to distinguish the triggered eruptions from those that would have happened independently from the seismic event. Delayed eruptions may be influenced by small (though permanent) static stress changes and/or dynamic strains, but assessing the relative contributions of these stresses is difficult (Manga and Brodsky, 2006). Viscoelastic relaxation of coseismic shear stresses is suggested as a potential trigger for delayed, post-seismic earthquakes (e.g., Freed and Lin, 2001), and may also influence earthquakevolcano interactions and result in delayed triggering of eruptions (e.g., Hill et al., 2002).

We examine here possible delayed, triggered eruptions by analyzing the response of the mud volcanoes of Azerbaijan to the earthquakes that hit this region in 2000. Azerbaijan is the most numerous onshore collection of mud volcanoes worldwide (around 300; Aliyev et al., 2009), and they thus provide through their large number an opportunity to evaluate the effect of stresses on eruptions.

\subsection{Mud volcano eruptions in Azerbaijan, and the response to the 2000 Baku earthquakes}


387 eruptions have been reported at 93 different mud volcanoes of Azerbajian during the period 1810-2007 (Aliyev et al., 2009). Interestingly, the number of mud volcano eruptions has shown a marked increase in the year following the 2000 Baku seismic sequence (Mellors et al., 2007), which includes some of the largest earthquakes in this region (Fig. 8). The increase of eruption frequency after this seismic sequence has also been noted and interpreted by Babayev et al. (2014). The main seismic events were two nearly simultaneous earthquakes offshore Baku on 25 November 2000. The two earthquakes occurred within two minutes, and both events showed normal faulting focal mechanisms with moment magnitudes $(\mathrm{Mw})$ of 6.8 and 6.5, and focal depths of 15 and $26.4 \mathrm{~km}$, respectively (Centroid Moment Tensor solutions catalog; http://www.globalcmt.org/); USGS reports the same magnitudes but much greater focal depths (50.3 and $33 \mathrm{~km}$, respectively; http://earthquake.usgs.gov). Jackson et al. (2002) revised the events and inferred lower magnitudes (Mw 6.2 and 6.1), and focal depths of 25 and $35 \mathrm{~km}$ depth, respectively.

The great number of mud volcanoes, and the record of eruptions that followed the $2000 \mathrm{Baku}$ earthquakes, provide an opportunity to investigate the role of dynamic and static stresses in triggering eruptions. Mellors et al. (2007) found that the number of eruptions (16) in 2001 exceeds 3 times the standard deviation from the mean, and determine a weak correlation between these events and the delayed increase (up to a year) in mud volcano activity. These authors do not suggest any potential mechanism, though they hint that eruptions might be related to near-field changes in stress that change groundwater levels. The mud volcano eruptions that occurred after the 2000 Baku earthquakes are located, with one exception, within $\sim 100 \mathrm{~km}$ of the epicenters (see Fig. 8; Table S8). This distance approximately corresponds to the upper bound on the expected triggering distance found in empirical relationships based on a global compilation of eruptions triggered within days of earthquakes (Manga et al., 2009). However, no short-term triggering has been reported followed the 2000 Baku earthquakes. If we assume that magnitude 6.2 earthquakes had rupture lengths of $\sim 16 \mathrm{~km}$ (Wells and Coppersmith, 
1994), then the majority of eruptions occurred 4-5 fault lengths $(60-75 \mathrm{~km})$ from the epicenters, while the observed maximum epicentral distance of $\sim 129 \mathrm{~km}$ is about 8 fault lengths (Table S8). Such distances are generally referred to as intermediate-field - distances great enough that static stress changes are considered to be small. A number of eruptions also occurred at epicentral distances of $\sim 30$ $\mathrm{km}$ ( 2 fault lengths), close to what is considered the near-field region (Table S8). Among these, most impressive was the flaming eruption of the Lokbatan mud volcano on 25 October 2001, 11 months after the main shocks (Fig.1f, g).

If the eruptions that followed the 2000 Baku earthquakes were initiated by the earthquakes, this raises the question of which processes control delayed eruptions in the near- to intermediate-field, and how the static and dynamic stresses contributed to the triggering. The mechanisms controlling a significant delay between earthquakes and eruptions are poorly understood, though diffusion of interstitial crustal fluids (water, melt) in response to static stress changes may be important (Hill et al., 2002). We thus investigate the magnitude and pattern of static stress changes caused by the 2000 seismic sequence, and the potential effects on the feeder systems of the mud volcanoes.

\subsection{Volumetric strain and static stress changes created by the 2000 Baku earthquakes}

A previous computation of static stress concluded that only seven eruptions, which occurred during the 3 years following the Baku earthquakes and within $60 \mathrm{~km}$ from the epicenters, could be related to crustal dilation (Babayev et al., 2014). To avoid overestimating the strain and static stress changes, we use the revised moment tensor solutions of Jackson et al. (2002), who propose the smallest moment magnitude, and we consider the focal depths recorded by the local Azerbaijan seismic network (Table S9). The 2000 Baku earthquakes indicate normal faulting parallel to the Caucasus belt. Though the significance of the normal faulting is not fully understood, it is likely that it resulted from the bending or down-dip extension of the N-directed subducting South Caspian slab (Priestley et al., 1994; 
Jackson et al., 2002; Knapp et al., 2004) (Fig. 8b). For this reason, earthquake ruptures are assumed to occur along the NE-dipping nodal planes (Fig. 8b; Table S9). 3D seismic experiments carried out in Azerbaijan have revealed the presence of gaseous mud reservoirs at depths of approximately $2-4 \mathrm{~km}$ (Cooper, 2001), and therefore volumetric strain is computed at an average depth of $3 \mathrm{~km}$ (Fig. S1).

The results of our static stress calculations indicate that the majority of the inferred fluid sources for the mud volcanoes that erupted during the December 2000-December 2001 time period lie in the contraction field (blue) produced by both earthquakes on 25 November 2000 (Fig. S1). The sign of volumetric strain thus appears to be correlated with eruptions, given that this volumetric contraction would pressurize the fluid source (Fig. S1). A few mud volcanoes fall in the dilatation field (red), including Lokbatan (number 10). However, it is likely that the Lokbatan volcano has its main fluid reservoir in the 6-12 $\mathrm{km}$ depth range (Kadirov et al., 2005), where the volumetric strain in fact becomes compressive (see cross sections in Fig.S1).

Unfortunately, there are orientation constraints for only some of the mud volcanoes. For instance, the large mud volcano Lokbatan is elongated and the Gotur gryphon field (which erupted in 2001) has aligned vents (Fig.9g, h). The geometric and spatial characteristics of the inferred feeder dikes (in terms of orientation, dimensions, position) and the magnitude of the normal stress changes are summarized in Table S8. Normal stress changes were evaluated at $1 \mathrm{~km}$ depth, more shallow than the assumed $3 \mathrm{~km}-$ deep reservoirs. Given that $\Delta \sigma_{\mathrm{n}}$ depends on the position and geometry of receiver dikes relative to the source faults, the patterns of normal stress changes are shown for the main orientations of the feeder dikes (i.e., $\mathrm{N} 30^{\circ} \mathrm{E}, \mathrm{N} 80^{\circ} \mathrm{E}$, and $\mathrm{N} 110^{\circ} \mathrm{E}$; Fig.9a-f).

Nearly all of the identified receiver dikes lie in unclamping regions created by both earthquakes of 25 November 2000 (Fig.9a-f; Table S8). Both earthquakes are expected to have contributed similar changes in normal stress, which should be additive. By contrast, the Mw5.2 earthquake of 07 January 
2001 (Fig. 8a) produced comparatively negligible normal stress changes on the mud volcanoes. Negligible stress changes would have also been those produced by the $\mathrm{M} \approx 706$ December 2000 earthquake, which occurred in Turkmenistan at an epicentral distance (440 to $465 \mathrm{~km}$ from Lokbatan mud volcano) beyond that for which other triggered eruptions have been reported (e.g., Manga et al., 2009).

The normal stress changes accumulated by both earthquakes are greatest at mud volcanoes around Baku, where unclamping stresses exceed 0.1 bar (0.01 MPa) at Lokbatan and Keyreki (Figs. 9af, S1; Table S8). At the more distant mud volcanoes, unclamping stress changes are very small, and generally fall in the range $10^{-2}-10^{-3}$ bar (Figs. 9a, f, S2; Table S8). The computed stress changes are best regarded as a lower limit, as there is some uncertainty about the actual earthquake magnitude; for instance, the magnitude Mw6.8 from the Centroid Moment Tensor solution catalog (Fig. 8a) would produce normal stress changes that at Lokbatan are one order of magnitude higher $(\sim 2$ bar at $1 \mathrm{~km}$ depth).

In summary, these results suggest that the majority of eruptions in the intermediate-field are correlated with concurrent pressurizing (squeezing) of the fluid source and unclamping of overlying, suitably-oriented feeder dikes (cf. Fig. 9a,f with Fig. S1). The latter may represent an efficient mechanism that may explain the triggering of eruptions at mud volcanoes situated relatively far from the epicentral area. In some cases the cumulative stress changes are smaller than tidal values, and thus the correlation with eruptions is uncertain.

\section{Mud volcano responses to multiple earthquakes}

\subsection{El Mayor-Cucapah 2010 (southern California) and local earthquakes}

Near the Salton Sea, Southern California, there are numerous hydrothermal features including mud pots, mound springs, gas vents, and one group of mud volcanoes near the intersection of Davis 
and Schrimpf roads in the vicinity of Niland, CA (Mazzini et al., 2011; Onderdonk et al., 2011) (Fig. 10). These mud volcanoes are associated with the Salton Sea Geothermal System and are driven by the escape of $\mathrm{CO}_{2}$ produced by metamorphic decarbonation reactions (Muffler and White, 1969), with a significant mantle source (Mazzini et al., 2011). It has been suggested that the mud volcanoes and other hydrothermal features in this area are associated with strike-slip faults parallel to, and representing perhaps, the southeastern-most extent of the San Andreas Fault system (Lynch and Hudnut, 2008). The Salton Sea itself is a pull-apart basin whose subsidence is accommodated by both right lateral slip on the San Andreas and Imperial/Superstition Hills faults and normal faulting within the Salton Trough (Brothers et al., 2009).

Rudolph and Manga (2010) documented the response of the Salton Sea mud volcanoes to the 04 April 2010 El-Mayor Cucapah earthquake. Gas discharge from the mud volcanoes increased by about a factor of two within two days after the earthquake and subsequently returned to pre-earthquake values over the course of 1-3 months. Rudolph and Manga (2012) documented one additional response and four non-responses of these mud volcanoes to five earthquakes that produced ground motions strong enough that a response was not unexpected based on empirical relationships between earthquake magnitude and epicentral distance (e.g. Wang, 2007; Manga et al. 2009). While Rudolph and Manga (2012) concluded that the observed changes in eruptive activity were most likely triggered by dynamic stresses associated with the passage of seismic waves, we revisit the static stress triggering hypothesis here by computing volumetric strain changes and normal stress changes on potential feeder dikes.

The geometry of the faults associated with the Salton Sea mud volcanoes is uncertain. We explore two different hypothetical fault geometries. First, a vertically-dipping fault with strike parallel to the trend of the San Andreas (Model A) and the proposed trends of the Brawley, Calipatria, and Red Hill faults (Fig. 10a, b). Second, we consider a fault (Model B) whose strike is parallel to the dominant trend of the northwest-dipping normal faults imaged beneath the Salton Sea, $\mathrm{S} 15^{\circ} \mathrm{W}$, and whose dip is 
$60^{\circ}$ to the northwest (Brothers et al., 2009). Of the six events documented in Rudolph and Manga (2012), we obtained focal mechanisms for the three events of 04 April 2010, 14 September 2010, and 15 December 2010 from the Southern California Seismic Network moment tensor catalog (Hutton et al., 2010) (Fig. 10a). A focal mechanism for the 29 February 2012 event was also computed (personal communication with Doug Dreger 2014) using two waveforms from stations CI.BOM and CI.RXH, obtained from the Southern California Earthquake Data Center (data.scec.org) and using methods described in Dreger and Helmberger (1993). Due to low signal-to-noise, it was not possible to obtain focal mechanisms for the two remaining events (02 April 2011 and 11 February 2012). For all events, we used the empirical fault geometry from Wells and Coppersmith (1994) and used the reported event location as the center of the fault.

Of the four earthquakes for which focal mechanisms are available, three produced unclamping stresses for the receiver fault in Model A, including both events that triggered increased eruptive activity. All four events produced unclamping stresses on the receiver fault in Model B. The $\mathrm{M}_{\mathrm{W}}$ 7.2 El Mayor-Cucapah earthquake produced by far the largest static stress changes, $\sim 0.1$ bar. The $\mathrm{M}_{\mathrm{W}} 3.87$ event of 29 February 2012 occurred at an epicentral distance of only $2.2 \mathrm{~km}$ from the mud volcanoes and produced static stress changes of $10^{-3}-10^{-2}$ bar. The sign of the stress change results in clamping for Model A and unclamping for Model B, and this event did not produce any measurable change in gas discharge or eruptive activity at the mud volcanoes. The remaining two events of 14 September 2010 and 15 December 2010 produced comparable changes, $10^{-5}$ bar in normal stress in Model A. For Model B, the 15 December 2010 event produced $10^{-4}$ bar normal stress change whereas the 14 September 2010 event produced $10^{-5}$ bar normal stress change. From Table S10, it is apparent that the events that triggered increased eruptive activity at the Salton Sea mud volcanoes differ from those that did not on the basis of seismic energy density, predicted using the empirical relationship in Wang (2007), but not on the basis of the sign or amplitude of the normal stress change on either of the fault models or on the 
basis of the sign of volumetric stress change. Moreover, the changes in static stress associated with the 14 September 2010 and 15 December 2010 events are exceedingly small, 100-1000 times smaller than stress changes that would be expected due to natural fluctuations in atmospheric pressure. Hence, it is unlikely that static stress changes are the dominant earthquake triggering mechanism at the Salton Sea mud volcanoes.

\subsection{Niikappu mud volcanoes (1952-2003), Hokkaido, Japan}

Near the town of Niikappu, Hokkaido, Japan, a series of mud volcanoes lie above the crest of an anticline, with the vents striking $\mathrm{N} 45^{\circ} \mathrm{W}$ (Fig. S3a, b). While not currently active, they erupted mud breccias several times in response to earthquakes. Chigira and Tanaka (1997) document 5 eruptions in response to earthquakes between 1952 and 1994, and Mellors et al. (2007) document a $6^{\text {th }}$ eruption in 2003. A previous analysis of these eruptions concluded that these mud volcanoes require a repose time of 1-2 years to return to a state that allows them to be triggered by earthquakes (Manga et al., 2009). Moreover, whether or not eruptions occur is better correlated with the amplitude of dynamic strains than the sign and magnitude of static volumetric stress changes (Manga et al., 2009). Here we revisit these previous studies and observations and also consider the effect of the earthquakes on the stress changes that act on the feeder dikes that likely underlie the mud volcanoes.

We assume that the feeder dike has the same orientation as the trend of the mud volcanoes. We use Coulomb 3.3 to calculate the change in normal stress on a vertical feeder dike with a strike of $\mathrm{N} 135^{\circ} \mathrm{E}$. We consider the responses to the 6 earthquakes compiled in Manga et al. (2009) that triggered eruptions and three that did not. Table S11 lists these events along with the volumetric strains and unclamping stresses on the feeder dikes. We observe no correlation between either the sign or magnitude of either the normal stress change or the volumetric strain and the triggering of eruptions at 
Niikappu. This analysis supports the previous conclusion (Manga et al., 2009) that responses are best correlated with the amplitude of dynamic stresses produced by seismic waves.

\subsection{Different triggers and responses at one mud volcano: a historical evaluation of the Montegibbio} mud volcano (Northern Apennines, Italy)

The Montegibbio mud volcano has a long historical record of eruptions since $91 \mathrm{BC}$ up to 1873 (Bonini, 2009). The main extrusive edifice is extinct, and minor residual activity occurs at small bubbling pools in the area. The oldest documented eruption occurred in $91 \mathrm{BC}$; Plinius (in his Historia Mundi Naturalis) described two sky-scraping flare and smoke columns that rose from the PedeApennine foothills nearly immediately after a destructive earthquake that hit west-southwest of Modena, in the Po Plain (Guidoboni, 1989; Casoli, 2001; CPTI Working Group, 2004). The location of this eruption is about $14.5 \mathrm{~km}$ from the $91 \mathrm{BC}$ macroseismic epicenter (Fig.6a, Table S12). Another large eruption occurred on April 5, 1781. A chronicle reports that some shaking was felt at Sassuolo around 10 PM of April 4, 1781, and the violent eruption of the volcano ( $3 \mathrm{~km}$ away) occurred the day after at ca. 12 am (Avv. Panini, in Calegari and Canestrini, 1867). This earthquake struck the Romagna region, approximately $80-90 \mathrm{~km}$ to the southwest from the volcano, with macroseismic magnitude $\mathrm{Mw}=6$.

The eruption of this mud volcano on June 4, 1835 was preceded by a violent rumble and a local earthquake that was felt in the region around the volcano; after that the volcano started to erupt, violently throwing mud and rock blocks several meters (ca. $40 \mathrm{~m}$ ) into the air, and small flames developed within the smoke column that accompanied the eruption (Dé Brignoli di Brunnhoff, 1836). The eruption was also accompanied by the development of large fractures in the ground, and the final outcome was a vast mud flow. No large earthquakes occurred in the days or months before the eruptions. However, a seismic sequence with two main events with Mw5.5 occurred in 1831 and 1832 
in the Reggio Emalia region, with macroseismic epicenters situated 30-35 km from the volcano (Fig. 6a). The last triggered eruption is mentioned by Mercalli (1883), a consequence of the Mw5.1 1873 earthquake with macroseismic epicenter situated $12 \mathrm{~km}$ from the volcano (Fig. 6a, Table S12).

We evaluate the potential normal stress change produced by all these earthquakes on the feeder system of the Montegibbio mud volcano. On the basis of the alignment of extinct and active vents, the feeder dike is inferred to be oriented $\mathrm{N} 15^{\circ} \mathrm{E}$ (Bonini, 2012). Obviously focal mechanism solutions are not available for these events, and thus there are a number of uncertainties that influence the results of this computation, particularly ambiguities related to the precise location and magnitude of the historical earthquakes, as well as the geometry and kinematics of the causative faults. Nevertheless, keeping in mind these limitations, we infer the geometries of the source faults that produced the earthquakes of 91 $\mathrm{BC}$ and 1873 on the basis of available geological, structural and subsurface data consisting of detailed networks of seismic lines (see Boccaletti et al., 2004). In particular, both earthquakes are assumed to nucleate on the thrust system splaying ahead of the Pede-Apennine thrust, and buried beneath the Po Plain deposits (Fig,6b). The 1781 source is that proposed by the DISS Working Group (2010), a fault segment of the main Pede-Apennine thrust. The 1831 and 1832 earthquakes are both located northwest of Reggio Emilia (Rovida et al., 2011)(Fig.6a). The epicenter of the more recent Mw5.4 October 15, 1996 earthquake occurred very close to them, and presumably nucleated on the same structure. A detailed analysis of aftershocks identifies a NW-dipping backthrust associated with a NE-trending main thrust (Ciaccio and Chiarabba, 2002). We have thus assumed that both 1831 and 1832 earthquakes were generated on a similarly-oriented fault plane. For all events, we used the empirical fault geometry from Wells and Coppersmith (1994), with the seismic event location as the center of the fault.

Normal stress changes caused by the 91 BC events would have acted to close the inferred feeder dike with a magnitude exceeding 0.1 bar (Fig.11a; Table S12). The observation that Montegibbio erupted nearly synchronously with the earthquake suggests near-field triggering by dynamic stresses. 
The 1781 earthquake occurred in the far-field and produced very small clamping stresses (Fig.11b; Table S12). Directivity of seismic waves is likely to have been important because the fault strike is broadly aligned with the volcano. The short-term mud volcano eruption was therefore most likely triggered again by dynamic stresses. Both the 1831 and 1832 earthquakes produced unclamping stresses with magnitude similar to tidal stresses (Fig.11c; Table S12), and the 1835 eruption, if triggered, would have been a delayed response to these earthquakes. Finally, the 1873 earthquake produced some unclamping stresses on the feeder dike, but these are of the order of tidal stresses and thus the role of normal stress changes in the short term triggering may be unimportant (Fig.11d; Table S12). In summary, the history of Montegibbio suggests that a given mud volcano may be sensitive to multiple triggering mechanisms, particularly short-term dynamic triggering in both the near- $(91 \mathrm{BC}$, 1873) and far-field (1781), as well as long-term (1835) responses in which normal stress changes unclamping the feeder dike may have played some role.

\section{Discussion}

The triggering or modulation of eruptions in the nine settings considered here differ in the temporal response to the earthquakes, and the changes in stress that are correlated with initiating eruptions or modulating ongoing eruptions. Fig. 12 shows a summary of all of the triggered mud volcano eruptions discussed here as well as the LUSI eruption. Also shown on Fig. 12 are contours of seismic energy density calculated using Equation 3 (Wang, 2007) and the characteristic rupture length (red) from Wells and Coppersmith (1994). On this magnitude-distance-triggering plot, we see that there is no clear division between those eruptions that occur shortly after an earthquake and those that occur in the months to years afterwards based on seismic energy density. We thus compare and contrast these responses to understand why some responses are rapid and others are delayed, and when and why static and dynamic stresses play a dominant role. 


\subsection{The 2000 Baku earthquakes and long-term interaction with static stress changes}

The stress changes caused by the November 2000 Baku earthquakes exceeded the minimum 0.1 bar conventionally-assumed threshold of static stress triggering (e.g., King et al., 1994; Stein, 1999) only at Lokhotan and Keyreki, while the majority of the other mud volcanoes experienced much smaller stress changes (0.001-0.01 bar), which are similar to, or even smaller than, those produced by solid Earth tides (0.01 bar; Table S8).

If mud volcanoes show sensitivity to tidal stresses, then we expect that even the small static stress changes produced by the 2000 Baku earthquakes would have exerted some effects on these systems. In the considered case, the static stress changes would have acted to encourage the opening of feeder dikes above a pressurized source, and may have thus played a role in the triggering of the delayed eruptions. Tidal stress changes have been proposed to influence eruptions and other geological events such as earthquakes (e.g., Tanaka et al., 2004). Indeed, a statistical study hypothesized that $60 \%$ of the mud volcano eruptions in Azerbaijan were controlled by tidal stresses (e.g., Guliyev and Feyzullayev, 1997). The ability of tidal stresses to trigger earthquakes is contentious. A number of studies have reported no correlation between Earth tides and earthquakes (e.g., Vidale et al., 1998), while a weak correlation has been more recently determined using the largest global earthquake catalog (Métivier et al., 2009). Other studies have reported a positive correlation between Earth tides and low frequency earthquakes (e.g. Thomas et al., 2012; Ide and Tanaka, 2014; Royer et al., 2015) and the eruptive activity of igneous volcanoes (e.g., Sparks, 1981; Kasahara, 2002), though the limited number of eruptions makes the latter assessment a challenge. Geysers, which are particularly sensitive to strain (e.g., Husen et al., 2004) and experience many eruptions, provide perhaps the best opportunity to assess whether tidal stresses influence eruptions. Early studies have proposed that geysers respond to tides and barometric pressure (Rinehart, 1972; Rojstaczer et al., 2003). However, the most recent analysis based 
on thousands of eruptions found no sensitivity to tides or barometric pressure changes (Hurwitz et al., 2014; Munoz-Saez et al. 2015).

Statistically significant links have also been observed between seismic events and eruptions of igneous volcanoes, months to a few years after an earthquake (Marzocchi, 2002; Watt et al., 2009). In particular, Bebbington and Marzocchi (2011) found that some volcanoes in Indonesia show statistical evidence of triggering over various temporal and spatial scales. These authors noted that if eruptions are driven by overpressure, the increase in internal pressure produced by the earthquake should exceed the critical threshold for direct triggering, otherwise the effect would not be observable. Assuming that all the increases in pressure are cumulative, even small stress increases produced by any earthquake may 'advance the clock' of the next eruption, implying that the susceptibility to the triggering is a property of the volcano system (Bebbington and Marzocchi, 2011). That is, only volcanoes that are sufficiently close to eruption may respond to the stress changes caused by an earthquake. If so, volcanoes that have been quiescent for long periods may be more predisposed to erupt (Eggert and Walter, 2009). It is noteworthy, then, that the earthquakes of 25 November 2000 occurred during a period that was comparatively quiescent (see the time-eruption histogram in Fig.8c). This analysis is straightforward for the Keyreki and Lokbatan mud volcanoes, because at the time of the $2000 \mathrm{Baku}$ earthquakes both had been in repose for about 10 years (Aliyev et al., 2009), and both experienced a stress increase that reached the conventional threshold for static stress triggering ( $0.1 \mathrm{bar})$. If the statistical significance of the increased eruption rate determined after the 2000 Baku earthquakes is valid, this would suggest that a significant fraction of the eruptions were triggered. We cannot discriminate between those truly triggered (but still delayed) and those that would have occurred anyway, because we lack information about the state of each mud volcano prior to the earthquakes. Nonetheless, the actual occurrence of even a few delayed eruptions would imply a process that converts the static stress and the transient dynamic stress into a permanent increase of internal pressure (e.g., 
Manga and Brodsky, 2006). Babayev et al. (2014) deduced that dynamic strain has been the dominant factor in driving eruptions over the five years following these earthquakes.

It is unexpected that the Baku earthquakes did not produce any immediate triggering of eruptions given the great number of mud volcanoes in the region and previous earthquakes in the region did trigger eruptions within days of the earthquakes. Many of the onshore mud volcanoes are supposedly sourced by feeder dikes with preferential orientation in the interval $\mathrm{N} 20^{\circ}-40^{\circ} \mathrm{E}$ (Bonini, 2012). Both Mw6.2 and Mw6.1 25 November 2000 earthquakes would have produced normal stress changes that would have clamped the $\mathrm{N} 20^{\circ}-40^{\circ}$ E-trending feeder dikes (see Fig.S4). From a static stress perspective, the results are thus generally consistent with the observed post-seismic inactivity of the mud volcanoes. We hypothesize that some delayed eruptions in Azerbaijan were the result of the static stress changes (compressing the mud source, and unclamping the feeder dikes) 'advancing the clock' of eruptions (Bautista et al., 1996; Nostro et al., 1998).

\subsection{Short-term static stress interaction}

In the examples studied here, we did not document direct triggering of new eruptions, except perhaps offshore Pakistan. But we could assess the effect of static stress changes on dormant mud volcanoes (Romania; Taiwan; northern Italy; Japan; Andaman Islands) or increasing the activity of an already erupting system (LUSI; southern California). Dynamic stresses are likely to play a central role in the short-term triggering of eruptions, a conclusion that requires that we also evaluate the static stress changes.

The Emilia mud volcanoes apparently increased their activity where the computed unclamping stresses are highest, though the stress changes were still modest, similar to those produced by Earth tides (Table S5). We also note that some mud volcanoes at greater distances from the epicenter $(\sim 63$

$\mathrm{km}$ for Casola-Querzola and Regnano) had a more pronounced response than those closer to the 
epicenter (52 and $55 \mathrm{~km}$ for Nirano and Puianello, respectively), where dynamic stresses are presumably higher (Table S5). This behavior might result from the different state of mud volcanoes, with some systems more susceptible to respond than others, or from the focusing of seismic wave energy, volcanoes being preferentially triggered by distant earthquakes when aligned with the fault in the direction of rupture (Delle Donne et al., 2010). However, rupture directivity is unlikely to have been important in the studied examples, and we also lack information regarding the pre-seismic state of the mud volcanoes. Given the small magnitude of static stress changes, their role in the short term is unclear.

In six other settings (Romania, Taiwan, Japan, Pakistan, Andaman Islands, and California) there were short-term responses to earthquakes. Possibly-new activity offshore of Pakistan, renewed activity at the Niikappu mud volcanoes, and increased gas flux at the Salton Sea mud volcanoes are not correlated with unclamping of feeder dikes and the triggered eruptions are most probably dominated by the dynamic stresses. In Romania and Taiwan unclamping stresses are well above the conventional threshold for the triggering, and hence are likely to have played a significant role in the mud volcano eruptions. Unclamping stress in Andaman Islands are instead slightly less than tidal stresses and are thus likely to be irrelevant to the short-term triggering of the mud volcano eruption.

\subsection{Response to dynamic rather than static stresses}

While most of the eruptions in Azerbaijan and some of those in the Apennines are seemingly associated with unclamping feeder dikes, the Pakistan, Niikappu and Salton Sea mud volcanoes do not appear to be sensitive to the static stress changes they experienced, and responses are better correlated with the amplitude of dynamic stresses. In some cases (Romania and Taiwan), however, the unclamping stresses are still large (1-3 bar) so static stress changes may still have played a role. Given 
the feeble unclamping stresses $(<0.01$ bar $)$, the eruption in Andaman Islands is instead likely to have been dominated by dynamic stresses.

The Salton Sea mud volcanoes differ from those in Azerbaijan and other settings (Romania, Italy, Taiwan, Japan, Andaman Islands) in that there is little net extrusion of mud and the mud erupts continuously. One explanation for the insensitivity of the Salton Sea mud volcanoes to static stress changes is that gas ascends through pathways (pore networks or cracks) whose geometry is not significantly affected by changes in normal stress but whose permeability is enhanced through the removal of particulate blockage or trapped bubbles (Beresnev, 2006; Beresnev and Deng, 2010) by the passage of seismic waves. The latter mechanism was invoked by Rudolph and Manga (2012) to explain the apparent sensitivity to the frequency of seismic waves.

\section{Conclusions}

Our observations and analyses allow us to use two complementary approaches to understand how earthquakes affect eruptions: first we identified the responses of sets of mud volcanoes to individual earthquakes in Azerbaijan, Romania, Taiwan, Andaman Islands, Pakistan, and Italy, and second the response of mud volcanoes in Japan, Italy and in California to multiple earthquakes. In the first case the analysis allows us to assess how the spatial variation of stress influences new eruptions and the discharge rate. In the second case we can assess how a single feature responds to different external stresses. In Azerbaijan, most of the eruptions that occur within a year of the earthquakes occur in regions where static stress changes caused the mud source to contract and the feeder dikes to widen. There are a few exceptions, however, suggesting that dynamic stresses played a role or that the earthquakes did not influence the eruptions. The permanent stress changes are small, typically 0.001 to 0.1 bar, so we suggest that the earthquake caused the eruptions to occur earlier than they might 
otherwise. This also explains why the eruptions are not triggered within days of the earthquakes. In other cases, where feeder dikes were unclamped, mud volcanoes responded within days.

In Taiwan and Romania mud volcanoes occur in the near field of an earthquake where unclamping stress changes are relatively large (they may approach or exceed 1 bar). In the Andaman Islands and Italy we also find that eruptions and discharge rate increases where the static stress changes unclamp feeder dikes. However, the stress changes are small (of the order of Earth tides, 0.01 bar) and thus their contribution would have been negligible relative to dynamic stresses, though in Italy we note that mud volcano activity is highest where unclamping stresses are highest. In contrast, in Japan and for the new island off the coast of Pakistan, renewed activity at the mud volcanoes is not accompanied by unclamping of feeder dikes, and may result from dynamic stresses only. In California, the studied mud volcanoes continuously discharge gas but little mud; here we find that static stress changes have little effect and increases in gas discharge are best correlated with the amplitude of seismic waves. The responses may be due to bubbles being mobilized by the passage of seismic waves. When static stress changes play a role in triggering, the examples discussed herein show that mud volcano eruptions occur for both contractional and dilatational volumetric strain; therefore, clamping/unclamping of the feeder dike may be the dominant discriminating factor for static stress triggering.

Taken together, the responses in these various field settings reveal that there is no single way in which mud eruptions respond to the stress changes produced by earthquakes. Responses depend of whether the eruption is ongoing and the processes causing mud to erupt - triggering may be rapid or delayed, and mud eruptions may show different sensitivity to static and dynamic stress changes. The responses of a given mud volcano may also reflect different triggering mechanics, as inferred for the now-extinct Monteggibbio mud volcano in the Northern Apennines. In general, dynamic stresses are likely to exert the dominant control on the triggering. In some cases, however, static stress changes are large enough ( 0.1 to 3 bar) to suppose that they have been influential. Static stress changes of $\sim 0.2$ bar 
are shown to be more effective than peak dynamic stresses (more than one order of magnitude higher) in activating or shutting down remote faults (Sevilgen et al., 2012). If mud volcano systems show the same sensitivity to stress changes, the role of static stresses should still be evaluated when trying to understanding eruption triggering processes.

\section{Acknowledgements}

We thank two anonymous reviewers for their constructive comments that helped to clarify several points. We also thank I. Sumita and A. Namiki for leading the field trip to the Niikappu mud volcanoes. D. Dreger computed one of the focal mechanisms in the Imperial Valley, California. MM and MR were supported by the US National Science Foundation. MB was supported by the Italian National Research Council (CNR). 


\section{References}

Aliyev, A.A., Guliyev, I.S., Rahmanov, R.R., 2009. Catalogue of recorded of mud volcano eruptions of Azerbaijan (1810-2007), Second Edition, 'Nafta-Press' Publishing-House, Baku, 109 pp.

Ammon, C.J., Ji, C., Thio, H-K., Robinson, D., Ni, S., Hjorleifsdottir, V., Kanamori, H., Lay, T., Das, S., Helmberger, D., Ichinose, G., Polet, J., Wald, D., 2005. Rupture process of the 2004 SumatraAndaman Earthquake. Science 308, no. 5725, 1133-1139.

Angelier, J., Chu, H.T., Lee, J.C., Hu, J.C., 2000. Active faulting and earthquake hazard: the case study of continuous monitoring of the Chihshang Fault, Taiwan. Journal of Geodynamics 29, 151-185.

Anzidei, M., Maramai, A., Montone, P. (Eds.), 2012. The Emilia (northern Italy) seismic sequence of May-June, 2012: preliminary data and results. Annals of Geophysics 55, no. 4, doi: 10.4401/ag-6110.

Avouac, J-P., Ayoub, F., Wei, S., Ampuero, J.-P., Meng, L., Leprince, S., Jolivet, R., Duputel, Z., Helmberger, D., 2014. The 2013, Mw7.7 Balochistan earthquake, energetic strike-slip reactivation of a thrust fault. Earth and Planetary Science Letters 391, 128-134.

Babayev, G., Tibaldi, A., Bonali, F.L., Kadirov, F., 2014. Evaluation of earthquake-induced strain in promoting mud eruptions: the case of Shamakhi-Gobustan-Absheron areas, Azerbaijan. Natural Hazards 72, 789-808. 
Baciu, C., Etiope, G., 2005. Mud volcanoes and seismicity in Romania. In: Martinelli, G., Panahi, B. (Eds.), Mud volcanoes, Geodynamics and Seismicity. NATO series, Springer Verlag Berlin, 77-87.

Baciu, C., Caracausi, A., Etiope, G. Italiano, F., 2007. Mud volcanoes and methane seeps in Romania: main features and gas flux. Annals of Geophysics 50, 501-511.

Barrientos, S.E., 1994. Large thrust earthquakes and volcanic eruptions. Pure and Applied Geophysics $142,225-237$.

Bautista, B.C., Bautista, M.L.P., Stein, R., Barcelona, E.S., Punongbayan, R.S., Laguerta, E.P., Rasdas, A.R., Ambubuyog, G., Amin, E.Q., 1996. Relationship of regional and local structures to Mount Pinatubo activity. In: Newhall, C.G., Punongbayan, R.S. (Eds.), Fire and Mud: Eruptions and Lahars of Mount Pinatubo, Philippines. University of Washington Press, Seattle, pp. 351-370.

Bebbington, M.S., Marzocchi, W., 2011. Stochastic models for earthquake triggering of volcanic eruptions. Journal of Geophysical Research 116, B05204, doi:10.1029/2010JB008114.

Beresnev, I.A., 2006. Theory of vibratory mobilization of nonwetting fluids entrapped in pore constrictions. Geophysics 71, N47-N56.

Beresnev, I.A., Deng, W., 2010. Viscosity effects in vibratory mobilization of residual oil. Geophysics, 75, N79-N85. 
Bignami, C., Burrato, P., Cannelli, V., Chini, M., Falcucci, E., Ferretti A., Gori, S., Kyriakopoulos, C., Melini, D., Moro, M., Novali, F., Saroli, M., Stramondo, S., Valensise, G., Vannoli P., 2012. Coseismic deformation pattern of the Emilia 2012 seismic sequence imaged by Radarsat-1 interferometry. Annals of Geophysics 55, 789-795.

Boccaletti, M., Bonini, M., Corti, G., Gasperini, P., Martelli, L., Piccardi, L., Tanini, C., Vannucci, G., 2004. Seismotectonic Map of the Emilia-Romagna Region, Scale 1:250,000, with Explanatory Notes. S.EL.CA, Società Elaborazioni Cartografiche, Florence, Italy.

Bock, Y., Prawirodirdjo, L., Genrich, J.F., Stevens, C.W., McCaffrey, R., Subarya, C., Puntodewo, S.S.O., Calais, E., 2003. Crustal motion in Indonesia from Global Positioning System Measurements. , Journal of Geophysical Research 108, 2367, doi:10.1029/2001JB000324.

Bonali, F.L., 2013. Earthquake-induced static stress change on magma pathway in promoting the 2012 Copahue eruption. Tectonophysics 608, 127-137.

Bonali, F.L., Tibaldi, A., Corazzato, C., Tormey, D.R., Lara, L.E., 2013. Quantifying the effect of large earthquakes in promoting eruptions due to stress changes on magma pathway: The Chile case. Tectonophysics 583, 54-67.

Bonini, M., 2008. Elliptical mud volcano caldera as stress indicator in an active compressional setting (Nirano, Pede-Apennine margin, northern Italy). Geology 36, 131-134. 
Bonini, M., 2009. Mud volcano eruptions and earthquakes in the Northern Apennines and Sicily, Italy. Tectonophysics 474, 723-735.

Bonini, M., 2012. Mud volcanoes: Indicators of stress orientation and tectonic controls. Earth-Science Reviews 115, 121-152.

Brothers, D.S., Driscoll, N.W., Kent, G.M., Harding, A.J., Babcock, J.M., Baskin, R.L., 2009. Tectonic evolution of the Salton Sea inferred from seismic reflection data. Nature Geoscience 2, 581-584.

Brown, K.M., 1990. The nature and hydrogeologic significance of mud diapirism and diatremes for accretionary systems. Journal of Geophysical Research 95, 8969-8982.

Burg, J.-P., Bernoulli, D., Smit, J., Dolati, A., Bahroudi, A., 2008. A giant catastrophic mud-and-debris flow in the Miocene Makran. Terra Nova 20, 188-193.

Bursik, M., Renshaw, C., McCalpin, J., Berry, M., 2003. A volcanotectonic cascade: activation of range front faulting and eruptions by dike intrusion, Mono Basin-Long Valley Caldera, California. Journal of Geophysical Research 108 (B8), 2393, doi:10.1029/2002JB002032.

Calegari, M., Canestrini, G., 1867. Storia della Salsa di Sopra presso Sassuolo della sorgente della Salvarola e dei pozzi oleiferi di Montegibio. Ann. Soc. Nat. Modena 2, 151-168. 
Cannata, A., Di Grazia, G., Montallo, P., Aliotta, M., Patane, D., Boschi, E., 2010. Response of Mount Etna to dynamic stresses from distant earthquakes. Journal of Geophysical Research 115, B12304, doi: 10.1029/2010JB007487.

Casoli, S., 2001. Su un fenomeno naturale descritto da Plinio (nat. 2, 199) accaduto nel territorio modenese. In: Quilici, L., Quilici Gigli, S. (Eds.), Urbanizzazione delle campagne nell'Italia antica. L'Erma di Bretschneider, pp. 63-70. ISBN 8882651843.

Chan, C.H., Stein, R.S., 2009. Stress evolution following the 1999 Chi-Chi, Taiwan, earthquake: Consequences for afterslip, relaxation, aftershocks and departures from Omori decay. Geophys. J. Int. 177, 179-192; doi: 10.1111/j.1365-246X.2008.04069.x.

Chaudhuri, H., Ghose, D., Bhandari, R.K., Sen, P., Sinha, B., 2012. A geochemical approach to earthquake reconnaissance at the Baratang mud volcano, Andaman and Nicobar Islands. Journal of Asian Earth Sciences 46, 52-60.

Chigira, A., Tanaka, K., 1997. Structural features and the history of mud volcanoes in Southern Hokkaido, Northern Japan. Journal of the Geological Society of Japan 103, 781-791.

Ching, K.E., Rau, R.J., Zeng, Y., 2007. Coseismic source model of the 2003 Mw 6.8 Chengkung earthquake, Taiwan, determined from GPS measurements. Journal of Geophysical Research 112, B06422. doi:10.1029/2006JB004439. 
Ciaccio, M.G., Chiarabba, C., 2002. Tomographic models and seismotectonics of the Reggio Emilia region, Italy. Tectonophysics 344, 261-276.

Cloetingh, S.A.P.L., Burov, E., Matenco, L., Toussaint, G., Bertotti, G., Andriessen, P.A.M., Wortel, M.J.R., Spakman, W., 2004. Thermo-mechanical controls on the mode of continental collision in the SE Carpathians (Romania). Earth and Planetary Science Letters 218, 57-76.

Cocco, M., Rice, J.R., 2002. Pore pressure and poroelasticity effects in Coulomb stress analysis of earthquake interactions. Journal of Geophysical Research 107, 2030, doi: 10.1029/2000JB000138.

Cooper, C., 2001. Mud volcanoes of Azerbaijan visualized using 3D seismic depth cubes: the importance of overpressured fluid and gas instead of non-existent diapirs. Proceedings of the European Association of Geoscientists and Engineers, Conference on 'Subsurface Sediment Mobilisation', Gent, Belgium, September 2001, p. 71.

CPTI Working Group, 2004. Catalogo Parametrico dei Terremoti Italiani, versione 2004 (CPTI04), INGV, Bologna; http://emidius.mi.ingv.it/CPTI04/.

Crews, J. B., Cooper, C. A., 2014. Experimental evidence for seismically initiated gas bubble nucleation and growth in groundwater as a mechanism for coseismic borehole water level rise and remotely triggered seismicity. Journal of Geophysical Research 119, 7079-7091, doi:10.1002/2014JB011398. 
Davies, R.J., Swarbrick, R.E., Evans, R.J., Huuse, M., 2007. Birth of a mud volcano: East Java, 29 May 2006. Geological Society of America Today 17, 4-9.

Davies, R. J., Brumm, M., Manga, M., Rubiandini, R., Swarbrick, R., Tingay, M., 2008. The East Java mud volcano, 2006 to present): An earthquake or drilling trigger? Earth and Planetary Science Letters $272,627-638$.

Davies, R.J., Foulger, G.R., Mathias, S., Moss, J., Hustoft, S., Newport, L., 2013. Reply: Davies et al., 2012. Hydraulic fractures: How far can they go? Marine and Petroleum Geology 43, 519-521.

Dé Brignoli di Brunnhoff, G., 1836. Relazione accademica dell'ultima eruzione accaduta nel vulcanetto aereo cosìdetta Salsa di Sassuolo nel modenese e considerazioni geognostiche intorno alle salse e alle loro cause. Tipografia Torreggiani \& Compagno, Reggio, 64 pp.

Delle Donne, D., Harris, A.J.L., Ripepe, M., Wright, R., 2010. Earthquake-induced thermal anomalies at active Volcanoes. Geology 38, 771-774, doi: 10.1130/G30984.1.

Delisle, G., Von Rad, U., Andruleit, H., Von Daniels, C.H., Tabrez, A.R, Inam, A., 2002. Active mud volcanoes on- and offshore eastern Makran, Pakistan. International Journal of Earth Sciences 91, 93110.

DeMets, C., Gordon, R.G., Argus, D.F., Stein, S., 1990. Current plate motions. Geophysical Journal International 101, 425-478. 
Deville, E., Guerlais, S.-H., Callec, Y., Griboulard, R., Huyghe, P., Lallemant, S., Mascle, A., Noble, M., Schmitz, J., and Caramba working group, 2006. Liquefied vs stratified sediment mobilization processes: insight from the South of the Barbados accretionary prism. Tectonophysics 428, 33-47.

Diez, M., La Femina, P.C., Connor, C.B., Strauch, W., Tenorio, V., 2005. Evidence for static stress changes triggering the 1999 eruption of Cerro Negro Volcano, Nicaragua and regional seismic swarms. Geophysical Research Letters 32, L04309, doi:10.1029/2004GL021788.

DISS Working Group, 2010. Database of Individual Seismogenic Sources (DISS). Version 3.1.1: A compilation of potential sources for earthquakes larger than M 5.5 in Italy and surrounding areas. (http://diss.rm.ingv.it/diss/, (C) INGV 2010 - Istituto Nazionale di Geofisica e Vulcanologia).

Dreger, D.S., Helmberger, D.V., 1993. Determination of source parameters at regional distances with single station or sparse network data. Journal of Geophysical Research 98, 8107-8125.

Eggert, S., Walter, T.R., 2009. Volcanic activity before and after large tectonic earthquakes: Observations and statistical significance. Tectonophysics 471, 14-26.

Etiope, G., 2015. Natural Gas Seepage, The Earth's Hydrocarbon Degassing. Springer International Publishing Switzerland, pp. 199; DOI 10.1007/978-3-319-14601-0.

Evans, R.J., Stewart, S.A., Davies, R.J., 2008. The structure and formation of mud volcano summit calderas. Journal of the Geological Society of London 165, 769-780. 
Feuillet, N., Beauducel, F., Tapponnier, P., 2011. Tectonic context of moderate to large historical earthquakes in the Lesser Antilles and mechanical coupling with volcanoes. Journal of Geophysical Research 116, B10308, doi: 10.1029/2011JB008443.

Fischer, D., Mogollón, J.M., Strasser, M., Pape, T., Bohrmann, G., Fekete, N., Spiess, V., Kasten, S., 2013. Subduction zone earthquake as potential trigger of submarine hydrocarbon seepage. Nature Geoscience 6, 647-651.

Freed, A.M., Lin. J., 2001. Delayed triggering of the 1999 Hector Mine earthquake by viscoelastic stress transfer. Nature 411, 180-183.|

Fujita, E., Kozono, T., Ueda, H., Kohno, Y., Yoshioka, S., Toda, N., Kikuchi, A., Ida, Y., 2013. Stress field change around Mount Fuji volcano magma system caused by the Tohoku megathrust earthquake, Japan. Bulletin of Volcanology 75, doi: 10.1007/s00445-012-0679-9.

Gallego, A., Russo, R.M., Comte, D., Mocanu, V.,. Murdie, R.E, VanDecar, J.C., 2013. Tidal modulation of continuous nonvolcanic seismic tremor in the Chile triple junction region. Geochemistry, Geophysics, Geosystems 14, 851-863.

Ganas, A., Grecu, B., Batsi, E., Radulian, M., 2010. Vrancea slab earthquakes triggered by static stress transfer. Natural Hazards and Earth System Sciences 10, 2565-2577.

Geological Survey of India, 2003. A note on mud-volcano eruption in Baratang, middle Andamans on 18-02-2003, available at http://www.portal.gsi.gov.in/gsiImages/information/n_mudvol.pdf. 
Govoni, A., Marchetti, A., De Gori, P., Di Bona, M., Lucente, F.P., Improta, L., Chiarabba, C., Nardi, A., Margheriti, L., Piana Agostinetti, N., Di Giovambattista, R., Latorre, D., Anselmi, M., Ciaccio, M.G., Moretti, M., Castellano, C., Piccinini, D., 2014. The 2012 Emilia seismic sequence (Northern Italy): Imaging the thrust fault system by accurate aftershock location. Tectonophysics $622,44-55$.

Guidoboni, E. (Ed.), 1989. Viaggio nelle aree sismiche della Liguria, Basso Piemonte, Toscana, Emilia Romagna - coste e Appennino dal I secolo a.C. al 2000. Presidenza del Consiglio dei Ministri, Dipartimento della Protezione Civile, e Storia Geofisica Ambiente. Istituto Poligrafico e Zecca dello Stato, Roma, ISBN: 88-85213-11-1, 496 pp.

Guliyev, I.S., Feyzulayev, A.A., 1997. All about mud volcanoes. Nafta Press, Baku, 52 pp.

Harris, R.A., 1998. Introduction to special section: Stress triggers, stress shadows and implications for seismic hazard. Journal of Geophysical Research 103, 24,347-24,358.

Harris, R.A., Simpson, R.W., 1996. In the shadow of 1857 - the effect of the great Ft. Tejon earthquake on subsequent earthquakes in southern California. Geophysical Research Letters 23, 229-232.

Higgins, G.E., Saunders, J.B., 1974. Mud volcanoes — their nature and origin. In: Jung, P., Bolli, H.M., Panchaud, R., Saunders, J.B., Schaefer, H., Wiedenmayer, F. (Eds.), Contributions to the Geology and Paleobiology of the Caribbean and Adjacent Areas. Verhandlungen der Naturforschenden Gesellschaft von Basel, 84, pp. 101-152. 
Hill, D.P., Pollitz, F., Newhall, C., 2002. Earthquake-volcano interactions. Physics Today 55 (11), 4147.

Hurwirtz, S., Sohn, R.A., Luttrell, K., Manga, M., 2014. Triggering and modulation of geyser eruptions in Yellowstone National Park by earthquakes, earth tides, and weather. Journal of Geophysical Research 119, 1718-1737.

Husen, S., Taylor, R., Smith, R.B., Healser, H., 2004. Changes in geyser eruption behavior and remotely triggered seismicity in Yellowstone National Park produced by the 2002 M 7.9 Denali fault earthquake, Alaska. Geology 32, 537-540.

Hutton, K., Woessner, J., Hauksson, E., 2010. Earthquake Monitoring in Southern California for Seventy-Seven Years (1932-2008). Bulletin of the Seismological Society of America 100 (2), 423446; doi: 10.1785/0120090130.

Ide, S., Tanaka, Y., 2014. Controls on plate motion by oscillating tidal stress: Evidence from deep tremors in western Japan. Geophys. Res. Lett., 41, 3842-3850.

Istadi, B., Pramono, G., Sumintadireja, P., 2009. Modeling study of growth and potential geohazard for LUSI mud volcano: East Java, Indonesia. Marine and Petroleum Geology 26, 1724-1739.

Jackson, J., Priestley, K., Allen, M., Berberian, M., 2002. Active tectonics of the South Caspian Basin. Geophys. J. Int. 148, 214-245. 
Jiang, G.-J., Angelier, J., Lee, J.C., Chu, H.T., Hu, J.C., Mu, C.H., 2011. Faulting and mud volcano eruptions inside of the coastal range during the $2003 \mathrm{M}_{\mathrm{w}}=6.8$ Chengkung earthquake in eastern Taiwan. Terr. Atmos. Ocean. Sci., 22 (5), 463-473; doi: 10.3319/TAO.2011.04.22.01(TT).

Kadirov, F.A., Lerche, I., Guliyev, I.S., Kadyrov, A.G., Feyzullayev, A.A., Mukhtarov, A.Sh., 2005. Deep structure model and dynamics of mud volcanoes, southwest Absheron Peninsula (Azerbaijan). Energy Explor. Exploit. 23 (5), 307-332.

Kasahara, J., 2002. Tides, earthquakes, and volcanoes. Science 297, 348-349

Kassi, A.M., Khan, S.D., Bayraktar, H., Kasi, A.K., 2013. Newly discovered mud volcanoes in the Coastal Belt of Makran, Pakistan—tectonic implications. Arabian Journal of Geosciences, in press, doi: 10.1007/s12517-013-1135-7

Kilb, D., Gomberg, J. Bodin, P., 2000. Earthquake triggering by dynamic stresses. Nature 408, 570574.

Kilb, D., Gomberg, J., Bodin, P., 2002. Aftershock triggering by complete Coulomb stress changes, Journal of Geophysical Research 107, 2060; doi:10.1029/2001JB000202

King, G.C.P., 2014. Fault Interaction, Earthquake Stress Changes, and the Evolution of Seismicity. Treatise on Geophysics, Volume 4, Earthquake Seismology, Chapter 8, 225-255. 
King, G.C.P., Stein, R.S., Lin, J., 1994. Static stress changes and the triggering of earthquakes. Bulletin of the Seismological Society of America 84, 935-953.

Kioka, A., Ashi, J., Sakaguchi, A., Sato, T., Muraoka, S., Yamaguchi, A., Hamamoto, H., Wang, K., Tokuyama, H., 2015. Possible mechanism of mud volcanism at the prism-backstop contact in the western Mediterranean Ridge Accretionary Complex. Marine Geology 363, 52-64.

Knapp, C.C., Knapp, J.H., Connor, J.A., 2004. Crustal-scale structure of the South Caspian Basin revealed by deep seismic reflection profiling. Marine and Petroleum Geology 21, 1073-1081.

Kopf, A.J., 2002. Significance of mud volcanism. Rev. Geophys. 40 (2), 1005.

Kopf, A.J., 2008. Making calderas from mud. Nature Geoscience 1, 500-501.

Kopf, A., Deyhle, A., Lavrushin, V.Y., Polyak, B.G., Gieskes, J.M., Buachidze, G.I., Wallmann, K., Eisenhauer, A., 2003. Isotopic evidence (He, B, C) for deep fluid and mud mobilization from mud volcanoes in the Caucasus continental collision zone. International Journal of Earth Sciences 92, 407425.

Kukowski, N., Schillhorn, T., Huhn, K., von Rad, U., Husen, S., Flueh, E.R., 2001. Morphotectonics and mechanics of the central Makran accretionary wedge off Pakistan. Marine Geology 173, 1-19.

Kuochen, H., Wu, Y.M., Chen, Y.G., Chen, R.Y., 2007. 2003 Mw6.8 Chengkung earthquake and its related seismogenic structures. Journal of Asian Earth Sciences 31, 332-339. 
Kusumoto, S., Hamamoto, T., Fukuda, Y., Takahashi, A., 2015. Vertical movements of the Murono mud volcano in Japan caused by the Naganoken Kamishiro Fault Earthquake in 2014. Earth, Planets and Space 67: 53; DOI 10.1186/s40623-015-0223-1.

La Femina, P.C., Connor, C.B., Hill, B.E., Strauch, W., Saballos, A.J., 2004. Magma-tectonic interactions in Nicaragua: The 1999 seismic swarm and eruption of Cerro Negro volcano. Journal of Volcanology and Geothermal Research 137, 187-199.

Lin, J., Stein, R., 2004. Stress triggering in thrust and subduction earthquakes, and stress interaction between the southern San Andreas and nearby thrust and strike-slip faults. Journal of Geophysical Research 109, B02303, doi:10.1029/2003JB002607.

Lin, J., Stein, R.S., Meghraoui, M., Toda, S., Ayadi, A., Dorbath, C., Belabbes, S., 2011. Stress transfer among en echelon and opposing thrusts and tear faults: Triggering caused by the $2003 \mathrm{Mw}=6.9$ Zemmouri, Algeria, earthquake. Journal of Geophysical Research 116, B03305, doi:10.1029/2010JB007654.

Linde, A.T,, Sacks, I.S,. 1998. Triggering of volcanic eruptions. Nature 395, 888-890.

Lupi, M., Saenger, E.H., Fuchs, F., Miller, S.A., 2013. Lusi mud eruption triggered by geometric focusing of seismic waves, Nature Geoscience 6, 642-646, doi:10.1038/ngeo1884. 
Lupi, M., Suski Ricci, B., Kenkel, J., Ricci, T., Fuchs, F., Miller, S.A., Kemna, A., 2016. Subsurface fluid distribution and possible seismic precursory signal at the Salse di Nirano mud volcanic field, Italy. Geophys. J. Int. 204, 907-917; doi: 10.1093/gji/ggv454..

Lynch, D.K., Hudnut, K.W., 2008. The Wister mud pot lineament: southeastward extension or abandoned strand of the San Andreas Fault? Bulletin of the Seismological Society of America 98 (4), $1720-1729$.

Madonia, P., Cusano, P., Diliberto, I.S., Cangemi, M., 2013. Thermal anomalies in fumaroles at Vulcano island (Italy) and their relationship with seismic activity. Physics and Chemistry of the Earth 63, 160-169.

Manga, M., 2007. Did an earthquake trigger the May 2006 eruption of the Lusi Mud volcano? Eos, Transactions American Geophysical Union 88(18), 201; doi:10.1029/2007EO180009

Manga, M., Bonini, M., 2012. Large historical eruptions at subaerial mud volcanoes, Italy. Natural Hazards and Earth System Sciences 12, 3377-3386, doi:10.5194/nhess-12-3377-2012.

Manga, M., Brodsky, E.E., 2006. Seismic triggering of eruptions in the far field: volcanoes and geysers. Annual Review of Earth and Planetary Sciences 34, 263-291.

Manga, M., Brumm, M., Rudolph, M.L., 2009. Earthquake triggering of mud volcanoes. Marine and Petroleum Geology 26, 1785-1798. 
Manga, M., Beresnev, I., Brodsky, E.E., Elkhoury, J.E., Elsworth, D., Ingebritsen, S.E., Mays, D.C., Wang, C.-Y., 2012. Changes in permeability caused by transient stresses: Field observations, experiments and mechanisms. Rev. Geophys. 50, RG2004, doi:10.1029/2011RG000382.

Marzocchi, W., 2002. Remote seismic influence on large explosive eruptions. Journal of Geophysical Research 107, 2018, doi:10.1029/2001JB000307.

Mazzini, A., Etiope, G., Svensen, H., 2012. A new hydrothermal scenario for the 2006 Lusi eruption, Indonesia. Insights from gas geochemistry. Earth and Planetary Science Letters 317-318, 305-318.

Mazzini, A., Svensen, H., Akhmanov, G.G., Aloisi, G., Planke, S., Malthe-Sørenssen, A., Istadi, B., 2007. Triggering and dynamic evolution of LUSI mud volcano, Indonesia. Earth and Planetary Science Letters 261, 375-388.

Mazzini, A., Svensen, H., Etiope, G., Onderdonk, N., Banks, D., 2011. Fluid origin, gas fluxes and plumbing system in the sediment-hosted Salton Sea Geothermal System (California, USA). Journal of Volcanology and Geothermal Research 205, 67-83.

Mazzini, A., Svensen, H., Planke, S., Guliyev, I., Akhmanov, G.G., Fallik, T., Banks, D., 2009. When mud volcanoes sleep: Insight from seep geochemistry at the Dashgil mud volcano, Azerbaijan. Marine and Petroleum Geology 26, 1704-1715. 
Mellors, R., Kilb, D., Aliyev, A., Gasanov, A., Yetirmishli,G., 2007. Correlations between earthquakes and large mud volcano eruptions, Journal of Geophysical Research 112, B04304, doi:10.1029/2006JB004489.

Mercalli, G., 1883. Geologia d'Italia: vulcani e fenomeni vulcanici in Italia, Milano.

Métivier, L., de Viron, O., Conrad, C.P., Renault, S., Diament, M., Patau, G., 2009. Evidence of earthquake triggering by the solid earth tides. Earth and Planetary Science Letters 278, 370-375.

Morley, C.K., 2003. Outcrop examples of mudstone intrusions from the Jerudong anticline, Brunei Darussalam and inferences for hydrocarbon reservoirs. In: Van Rensbergen, P., Hillis, R.R., Maltman, A.J., Morley C.K. (Eds.), Subsurface Sediment Mobilization. Geological Society of London, Special Publications 216, 381-394.

Morley, C.K., Guerin, G., 1996. Comparison of gravity-driven deformation styles and behavior associated with mobile shales and salt. Tectonics 15, 1154-1170.

Morley, C.K., Crevello, P., Ahmad, Z.H., 1998. Shale tectonics and deformation associated with active diapirism: the Jerudong Anticline, Brunei Darussalam. Journal of the Geological Society of London $155,475-490$.

Mozziconacci, L., Delouis, B., Angelier, J., Hu, J.C., Huang, B.S., 2009. Slip distribution on a thrust fault at a plate boundary: the 2003 Chengkung earthquake, Taiwan. Geophysical Journal International 177, 609-623. 
Muffler, L. White, D., 1969. Active metamorphism of Upper Cenozoic sediments in the Salton Sea geothermal field and Salton trough, southeastern California. Geol. Soc. Am. Bull. 80, 157-182.

Mukhtarov, A.Sh., Kadirov, F.A., Guliyev, I.S., Feyzullayev, A.A., Lerche, I., 2003. Temperature evolution in the Lokbatan mud volcano crater (Azerbaijan) after the eruption of 25 October 2001. Energy Exploration \& Exploitation 21, 187-207.

Munoz-Saez, C., Manga, M., Hurwitz, S., Rudolph, M.L., Namiki, A., Wang, C.-Y., 2015. Dynamics within geyser conduits, and sensitivity to environmental conditions: Insights from a periodic geyser in the El Tatio Geyser Field, Atacama Desert, Chile, Journal of Volcanology and Geothermal Research $292,41-55$.

Nakamura, K., 1977. Volcanoes as possible indicators of tectonic stress orientation-principle and proposal. Journal of Volcanology and Geothermal Research 2, 1-16.

Nilforoushan, F., Masson, F., Vernant, P., Vigny, C., Martinod, J., Abbassi, M., Nankali, H., Hatzfeld, D., Bayer, R., Tavakoli, F., Ashtiani, A., Doerflinger, E., Daignières, M., Collard, P., Chéry, J., 2003. GPS network monitors the Arabia-Eurasia collision deformation in Iran. Journal of Geodesy 77, 411422.

Nostro, C., Stein., R.S., Cocco, M., Belardinelli, M.E., Marzocchi, W., 1998. Two-way coupling between Vesuvius eruptions and southern Apennine earthquakes, Italy, by elastic stress transfer, Journal of Geophysical Research 103, 24487-24504, doi:10.1029/98JB00902. 
Okada, Y., 1992. Internal deformation due to shear and tensile faults in a half-space. Bull. Seismol. Soc. Am. 82, 1018-1040.

Oncescu, M.C., Bonjer, K.P., 1997. A note on the depth recurrence and strain release of large Vrancea earthquakes. Tectonophysics 272, 291-302.

Onderdonk, N., Mazzini, A., Shafer, L., Svensen, H., 2011. Controls on the geomorphic expression and evolution of gryphons, pools, and caldera features at hydrothermal seeps in the Salton Sea Geothermal Field, southern California. Geomorphology 130, 327-342.

Pondrelli, S., Salimbeni, S., Perfetti, P., Danecek, P., 2012. Quick regional centroid moment tensor solutions for the Emilia 2012 (northern Italy) seismic sequence. Annals of Geophysics 55, 615-621, doi: 10.4401/ag-6146.

Priestley, K., Baker, C., Jackson, J., 1994. Implications of earthquake focal mechanism data for the active tectonics of the South Caspian Basin and surrounding regions. Geophysical Journal International $118,111-141$.

Reasenberg, P.A., Simpson, R.W., 1992. Response of regional seismicity to the static stress change produced by the Loma Prieta earthquake. Science 255, 1687-1690. 
Rinehart, J.S., 1972. Fluctuations in geyser activity caused by variations in earth tidal forces, barometric pressure, and tectonic stresses. Journal of Geophysical Research 77, 342-350.

Roberts, K.S., Davies, R.J., Stewart, S.A., 2010. Structure of exhumed mud volcano feeder complexes, Azerbaijan. Basin Research 22, 439-451.

Rojstaczer, S., Galloway, D.L., Ingebritsen, S.E., Rubin, D.E., 2003. Variability in geyser eruptive timing and its causes; Yellowstone National Park. Geophysical Research Letters 30, 18, 1953, doi:10.1029/2003GL017853

Rovida, A., Camassi, R., Gasperini P., Stucchi, M. (Eds.), 2011. CPTI11, the 2011 version of the Parametric Catalogue of Italian Earthquakes, Milano, Bologna, http://emidius.mi.ingv.it/CPTI, doi: 10.6092/INGV.IT-CPTI11 (http://emidius.mi.ingv.it/CPTI11/)

Royer, A.A., Thomas, A.M. Bostock, M.G., 2015. Tidal modulation and triggering of low-frequency earthquakes in northern Cascadia. J. Geophys. Res. Solid Earth, 120, 384-405.

Rubinstein, J.L., La Rocca, M., Vidale, J.E., Creager, K.C., Wech, A.G., 2008. Tidal Modulation of Nonvolcanic Tremor. Science 319, 186-189.

Rudolph, M.L., Manga, M., 2010. Mud volcano response to the 4 April 2010 El Mayor-Cucapah earthquake. Journal of Geophysical Research 115, B12211, doi:10.1029/2010JB007737. 
Rudolph, M.L. Manga, M., 2012. Frequency dependence of mud volcano response to earthquakes. Geophysical Research Letters 39, L14303, doi: 10.1029/2012GL052383.

Rudolph, M.L, Manga, M., Tingay, M., Davies, R., 2015. Influence of seismicity on the Lusi mud eruption. Geophysical Research Letters 42, 7436-7443; doi: 10.1002/2015GL065310.

Saraò, A., Peruzza, L., 2012. Fault-plane solutions from moment-tensor inversion and preliminary Coulomb stress analysis for the Emilia Plain. Annals of Geophysics 55, 647-654, doi: 10.4401/ag6134.

Sawolo, N., Sutriono, E., Istadi, B.P., Darmoyo, A.B., 2009. The LUSI mud volcano triggering controversy: Was it caused by drilling? Marine and Petroleum Geology 26, 1766-1784.

Schlüter, H.U., Prexl, A., Gaedicke, Ch., Roeser, H., Reichert, Ch., Meyer, H., von Daniels, C., 2002. The Makran accretionary wedge: sediment thicknesses and ages and the origin of mud volcanoes. Marine Geology 185, 219-232.

Schroeder, R., 1976. Reservoir engineering report for the MAGMA SDG\&E geothermal experimental site near the Salton Sea, CA, Report UCRL-52094, Lawrence Livermore Laboratory.

Selva, J., Marzocchi, W., Zencher, F., Casarotti, E., Piersanti, A., Boschi, E., 2004. A forward test for interaction between remote earthquakes and volcanic eruptions: the case of Sumatra (June 2000) and Denali (November 2002) earthquakes. Earth and Planetary Science Letters 226, 383-395. 
Sevilgen, V., Stein, R.S., Pollitz, F.F., 2012. Stress imparted by the great 2004 Sumatra earthquake shut down transforms and activated rifts up to $400 \mathrm{~km}$ away in the Andaman Sea. PNAS 109 (no. 38), 15152-15156.

Shirzaei, M., Rudolph, M.L. Manga, M., 2015. Deep and shallow sources for the Lusi mud eruption revealed by surface deformation. Geophysical Research Letters 42, doi:10.1002/2015GL064576.

Snead, R.E., 1964. Active mud volcanoes of Baluchistan, West Pakistan. Geographical Review 54, 546-560.

Sobissevitch, L., Gorbatikov, A.V., Ovsuchenko, A.N., 2008. Deep Structure of the Mt. Karabetov Mud Volcano. Doklady Earth Sciences 422, 1181-1185.

Sondhi, V.P., 1947. The Makran earthquake of 28th November 1945: the birth of new islands. Indian Mineral 1, 154-156.

Sparks, R.S.J., 1981. Triggering of volcanic eruptions by Earth tides. Nature 290, 448.

Steacy, S., Gomberg, J., Cocco, M., 2005. Introduction to special section: Stress transfer, earthquake triggering, and time-dependent seismic hazard. Journal of Geophysical Research 110, B05S01, doi:10.1029/2005JB003692. 
Stein, R.S., King, G.C.P., Lin, J., 1992. Change in failure stress on the southern San Andreas fault system caused by the 1992 magnitude 5 7.4 Landers earthquake. Science 258, 1328-1332.

Stein, R.S., 1999. The role of stress transfer in earthquake occurrence. Nature 402, 605-609.

Stewart, S.A., Davies, R.J., 2006. Structure and emplacement of mud volcano systems in the South Caspian Basin. AAPG Bulletin 90, 771-786.

Subarya, C., Chlieh, M., Prawirodirdjo, L., Avouac, J.-P., Bock, Y., Sieh, K., Meltzner, A.J., Natawidjaja, D.A., McCaffrey, R., 2006. Plate-boundary deformation associated with the great Sumatra-Andaman earthquake. Nature 440, 46-51.

Sumita, I., Manga, M., 2008. Suspension rheology under oscillatory shear and its geophysical implications. Earth and Planetary Science Letters 269, 467-476.

Sung, Q.C., Chang, H.C., Liu, H.C., Chen, Y.C., 2010. Mud volcanoes along the Chishan fault in Southwestern Taiwan: A release bend model. Geomorphology 118, 188-198.

Tanaka, S., Ohtake, M., Sato, H., 2004. Tidal triggering of earthquakes in Japan related to the regional tectonic stress. Earth Planets Space 56, 511-515.

Thomas, A. M., Bürgmann, R. Shelly D. R., Beeler N.M., Rudolph M. L., 2012. Tidal triggering of low frequency earthquakes near Parkfield, California: Implications for fault mechanics within the brittle-ductile transition. J. Geophys. Res., 117, B05301. 
Tingay, M.R.P., Hillis, R.R., Morley, C.K., Swarbrick, R.E. Okpere, E.C., 2003. Pore pressure/stress coupling in Brunei Darussalam — implications for shale injection. In: Van Rensbergen, P., Hillis, R.R., Maltman, A.J., Morley, C.K. (Eds.), Subsurface Sediment Mobilization. Geological Society, London, Special Publications 216, pp. 369-379.

Tingay, M., Rudolph, M.L. Manga, M., Davies, R., Wang, C.-Y., 2015. Initiation of the Lusi mudflow disaster. Nature Geoscience 8, 493-494, doi:10.1038/ngeo2472.

Toda, S., Stein, R.S., Richards-Dinger, K., Bozkurt, S., 2005. Forecasting the evolution of seismicity in southern California: Animations built on earthquake stress transfer. Journal of Geophysical Research 110, B05S16, doi:10.1029/2004JB003415.

Toda, S., Stein, R.S., Sevilgen, V., Lin, J., 2011. Coulomb 3.3 Graphic-Rich Deformation and StressChange Software for Earthquake, Tectonic, and Volcano Research and Teaching — User Guide. U.S. Department of the Interior, U.S. Geological Survey, Open-File Report 2011-1060, 63 pp.

Toda, S., Stein, R.S., Beroza, G.C., Marsan, D., 2012. Aftershocks halted by static stress shadows. Nature Geoscience 5, 410-413.

Tsai, Y.B., 1986. Seismotectonics of Taiwan. Tectonophysics 125, 17-38. 
Tsunogai, U., Maegawa, K., Sato, S., Komatsu, D.D., Nakagawa, F., Toki, T., Ashi, J., 2012. Coseimic massive methane release from a submarine mud volcano. Earth and Planetary Science Letters 341-344, $79-85$.

Vidale, J.E., Agnew, D.C., Johnston, M.J.S., Oppenheimer, D.H., 1998. Absence of earthquake correlation with Earth tides: an indication of high preseismic fault stress rate. Journal of Geophysical Research 103, 24567-24572.

Walter, T.R., 2007. How a tectonic earthquake may wake up volcanoes: Stress transfer during the 1996 earthquake-eruption sequence at the Karymsky Volcanic Group, Kamchatka. Earth and Planetary Science Letters 264, 347-359.

Walter, T.R., Amelung, F., 2007. Volcanic eruptions following M > 9 megathrust earthquakes: Implications for the Sumatra-Andaman volcanoes. Geology 35, 539-542.

Walter, T.R., Wang, R., Zimmer, M., Grosser, H., Lühr, B., Ratdomopurbo, A., 2007. Volcanic activity influenced by tectonic earthquakes: Static and dynamic stress triggering at Mt. Merapi. Geophysical Research Letters 34, L05304, doi:10.1029/2006GL028710.

Walter, T.R., Wang, R., Acocella, V., Neri, M., Grosser, H., Zschau, J., 2009. Simultaneous magma and gas eruptions at three volcanoes in southern Italy: An earthquake trigger? Geology 37, 251-254.

Wang, C.-Y., 2007. Liquefaction beyond the near field. Seismological Research Letters 78, 512-517. 
Wang, C.-Y., Manga, M., 2010. Hydrologic responses to earthquakes and a general metric. Geofluids $10,206-216$.

Watt, S.F.L., Pyle, D.M., Mather, T.A., 2009. The influence of great earthquakes on volcanic eruption rate along the Chilean subduction zone. Earth and Planetary Science Letters 277, 399-407.

Wells, D.L., Coppersmith, K.J., 1994. New empirical relationships among magnitude, rupture length, rupture width, rupture area, and surface displacement. Bull. Seismol. Soc. Am. 84, 974-1002.

Wu, Y.M., Chen, Y.G., Shin, T.C., Kuochen, H., Hou, C.S., Hu, J.C., Chang, C.H., Wu, C F., Teng, T.L., 2006. Coseismic versus interseismic ground deformations, fault rupture inversion and segmentation revealed by 2003 mw 6.8 Chengkung earthquake in eastern Taiwan. Geophysical Research Letters 33, L02312, doi:10.1029/2005GL024711.

You, C.F., Gieskes, J.M., Lee, T., Yui, T.F., Chen, H.W., 2004. Geochemistry of mud volcano fluids in the Taiwan accretionary prism. Applied Geochemistry 19, 695-707. 


\section{Figure Captions}

Figure 1. Characteristics of mud volcano features from Azerbaijan. (a) Large gas bubble typically popping up a crater atop a gryphon at Ayran Tekan mud volcano; hammer (circled) for scale (N39.99389 E49.30889; photo 23 May 2010). (b) Gryphon emitting a fresh mud flow in the KichikMaraza mud volcano field (N40.51028 E49.03194; photo 22 June 2013). (c) Alignment of mud cones mud cones and gryphons at Gotur (extracted from Google Earth®, http://earth.google.it/downloadearth.html). (d) Lateral view of the large Kjanizadag mud volcano edifice (N40.14083 E49.38222; photo 21 June 2013). (e) Small caldera topping the gentle-sided Kichik Bahar mud volcano (N39.99805 E49.45527; photo 25 May 2010). (f) Flaming eruption at the Lokbatan mud volcano on 25 October 2001; photo by Phil Hardy — from BBC NEWS 29th October 2001, Clare Doyle in Baku. According to Mukhtarov et al. (2003), this violent explosive eruption was characterized by an initial flame approximately $300 \mathrm{~m}$ tall and $100 \mathrm{~m}$ across. (g) Lateral view of the summit crater of Lokbatan (N40.30444 E49.70916; photo 27 June 2014); person (circled) for scale.

Figure 2. (a) Tectonic sketch map of the Carpathian fold-and-thrust belt. Epicenter and focal mechanism of the Mw7.4 04 March 1977 Vrangea earthquake are reported form Oncescu and Bonjer (1997). (b) Oblique view of the $20 \mathrm{~km}$-long Berca-Arbanasi fold anticline, which exposes four mud volcano fields along its axis (from North to South), Beciu, Paclele Mici, Paclele Mari and Fierbatori. (c) Satellite image showing the aligned vents within the area of active seepage atop the Paclele Mari mud volcano edifice. (b) and (c) are extracted from Google Earth®, http://earth.google.it/downloadearth.html. (d) Normal stress changes $\left(\Delta \sigma_{\mathrm{n}}\right.$; bar, unclamping positive) imparted by the 1977 Vrancea 
earthquake. Berciu (Be) and Paclele Mari (PMa) mud volcanoes are indicated. Stresses are computed on $\mathrm{N} 08^{\circ} \mathrm{E}$ orientated vertical receiver dikes (black bar); the example reports the result obtained from the source model proposed by Oncescu and Bonjer (1997) and Ganas et al. (2010) (Table S1). The model also considers a 50-patch source. (e) Cross section of normal stress changes. The blue dashed line indicates the horizontal section (1 km depth) of stress change distribution shown in panel (d).

Figure 3. (a) Tectonic sketch map of the western Indonesian archipelago. The red arrows indicate plate velocities of India relative to the Sunda Shelf block (Subarya et al., 2006). Dark blue arrows indicate computed (contraction/extension) principal surface strain rates (Bock et al., 2003). (b) Detail of Andaman Islands showing earthquakes with $M \geq 5$ of 26 and 27 December 2004, and distance from the Baratang mud volcano that erupted after the Mw9.1 earthquake. Focal mechanism solution of 26 December 2004 earthquake and seismicity around the Andaman Islands are from USGS (http://earthquake.usgs.gov). (c) Normal stress changes $\left(\Delta \sigma_{\mathrm{n}}\right.$; bar, unclamping positive) produced by the Great Sumatra earthquake of 26 December 2004. Stress changes are computed for a vertical $\mathrm{N} 25^{\circ}$ E-trending dike (black bar), which is supposedly controlling the mud volcano in Baratang (Andaman-Nicobar Islands) that erupted immediately after the earthquake. The fault model considers a 450-patch source model (downloaded at http://www.seismo.ethz.ch/static/srcmod/Homepage.html; Ammon et al., 2005), with $\mathrm{Mw} \approx 9$, fault strike $=320^{\circ} \mathrm{E}, \operatorname{dip}=15^{\circ}$, length $=450 \mathrm{~km}$, width $=180 \mathrm{~km}$, rake= 91.7. Stress is sampled at $1 \mathrm{~km}$ depth.

Figure 4. (a) Tectonic sketch map of southeastern Taiwan. Epicenter and focal mechanism of the Mw6.8 10 December 2003 Chengkung earthquake are reported form Wu et al. (2006). (b) Hypocenters of the 2003 Chengkung earthquake sequence delineating the listric geometry of the causative 
Chihshang Fault (redrawn from Wu et al., 2006). (c) Normal stress changes $\left(\Delta \sigma_{\mathrm{n}}\right.$; bar, unclamping positive) imparted by the 2003 Chengkung earthquake. Stresses are computed on $\mathrm{N} 85^{\circ} \mathrm{E}$ orientated vertical receiver dikes (black bar); the example reports the result obtained from the source model proposed by Wu et al. (2006) (Table S3). Luoshan (Lu) and Leikunghuo (Le) mud volcanoes are indicated. (d) Cross section showing normal stress changes. The blue dashed line indicates the horizontal section (1 km depth) of stress change distribution shown in panel (c).

Figure 5. (a) Tectonic sketch map of the Makran accretionary wedge of south-eastern Iran and southern Pakistan (compiled from Snead, 1964; Kukowski et al., 2001; Schlüter et al., 2002; Burg et al., 2008). The black arrows show GPS horizontal velocities in a Eurasia-fixed reference frame (after Nilforoushan et al., 2003). The blue arrows indicate relative plate motion and convergence velocities (DeMets et al.,1990; Kukowski et al., 2001). Focal mechanism solution of 24 September 2013 earthquake from USGS (http://earthquake.usgs.gov). (b) Satellite image (26 September 2013) of the new island offshore Gwadar. Satellite images (extracted from Google Earth®) showing the (c) elongated Tang mud volcano, and (d) vent alignments and an elongated volcano in the Ormara field. (e, f) Normal stress changes $\left(\Delta \sigma_{\mathrm{n}}\right.$; bar, unclamping positive) produced by the $\mathrm{Mw}=7.7$ Balochistan earthquake of 24 September 2013. Stress changes are computed for different orientations of possible vertical receiver dikes (black bar) that are inferred to have controlled the mud volcano system that spawned the new island (red circle) that appeared offshore Gwadar shortly after the earthquake (see Table S4). The fault model considers a 7-patch source (after Avouac et al., 2014), as well as a uniform rake=6. Stress is sampled at $1 \mathrm{~km}$ depth. 
Figure 6. (a) Geological setting of the external Northern Apennines (northern Italy). Focal mechanism solutions of main earthquakes of the May-June 2012 Emilia seismic sequence are reported (from INGV, TDMT; http://cnt.rm.ingv.it/tdmt.html); numbers indicate earthquake chronology: 1, M=4.3 (19 May 2012); 2, M=6.1 (20 May 2012); 3, M=4.9 (20 May 2012); 4, M=5.1 (20 May 2012); 5, M=4.5 (20 May 2012); 6, M=5.9 (29 May 2012); 7, M=5.3 (29 May 2012); 8, M=4.9 (29 May 2012); 9, M=5.1 (03 June 2012). The modeled coseismic deformation field detected through InSAR analysis is reported (after Bignami et al., 2012). (b) Schematic crustal-scale cross section through the Northern Apennines and Po Plain. Hypocenters of main 2012 earthquakes (after Saraò and Peruzza, 2012) are projected onto the NNE-SSW striking profile. Computed changes of normal stress $\left(\Delta \sigma_{n}\right.$; bar, unclamping positive) produced by the $\mathrm{Mw}=6.120$ May and $\mathrm{Mw}=5.929$ May 2012 earthquakes (panels $\mathrm{c}$ and d, respectively). Normal stress changes are computed on average $\mathrm{N} 10^{\circ} \mathrm{E}$-oriented vertical dikes (black bar), which are inferred to be the dominant feeder system of mud volcanoes (e.g., Bonini, 2012). Fault parameters (Table S6) are taken from the inversion of the SAR dataset (Bignami et al., 2012), and the empirical scaling of Wells and Coppersmith (1994). The fault (surface projection in green) is $\sim 12$ $\mathrm{km}$ and $\sim 9 \mathrm{~km}$ long, with $\sim 0.56 \mathrm{~m}$ and $\sim 0.48 \mathrm{~m}$ of tapered reverse slip for the $\mathrm{Mw}=6.1$ and $\mathrm{Mw}=5.9$ earthquakes, respectively. Stress is sampled at $1 \mathrm{~km}$ depth. The thick red line indicates the PedeApennine thrust. The red circles indicate the mud volcanoes that increased their activity within few days after the seismic events, in green those that did not show apparent response, and in white those that have not been inspected. Mud volcanoes: To, Torre; Ca, Casola-Querzola; Re, Regnano; Ni, Nirano; Pu, Puianello; Os, Ospitaletto.

Figure 7. (a) Satellite image (August 2012) showing the LUSI mud volcano in east Java (S7.52718 E112.71166). Image extracted from Google Earth®. (b) Location of LUSI and the Mw 6.3 Yogyakarta 
earthquake that hit central Java on 26 May 2006. Focal mechanism solution from USGS (http://earthquake.usgs.gov). (c) Discharge at LUSI (black line, left vertical axis), digitized from Figure 5 in Mazzini et al. (2007), and earthquakes (red stars) from the USGS catalog within $1500 \mathrm{~km}$ of LUSI. The vertical position of each seismic event corresponds to the calculated seismic energy density at LUSI (right vertical axis - note log scale). (d) Same as (c) except that we position each seismic event vertically based on the calculated peak ground velocity using the empirical attenuation relationship for East Java from Davies et al. (2008).

Figure 8. (a) Schematic structural map of the Greater Caucasus-eastern Caspian Basin (modified after Jackson et al., 2002). (b) Regional cross section through the Absheron Sill and the South Caspian Basin (modified from Knapp et al., 2000). (c) Main structures and mud volcano fields between the Greater Caucasus front and Absheron Peninsula in Azerbaijan. Earthquake epicenters and magnitude (Mw) are from Jackson et al. (2002) and global Centroid Moment Tensor solutions catalog (http://www.globalcmt.org/); the magnitude $\mathrm{Mw}$ in parenthesis refers to Centroid Moment Tensor solutions. The NE-dipping normal faults in the oceanic crust (b) are hinted to be the causative faults of the 2000 seismic sequence. Mud volcanoes that erupted after the 25 November 2000 earthquakes (period Dec.2000-Dec. 2001, in roughly chronologic order) are (Mellors et al., 2007; Aliyev et al., 2009) (Table S8): 1, Akhtimer (Agtirma); 2, Durandag; 3, Buzovna-sopkasi (Pilpila-Buzovna); 4, Gotur; 5, Chapylmish; 6, Solakhai; 7, Dashgil; 8, Chigil-deniz; 9, Keyreki; 10, Lokbatan; 11, BozdagGekmaly; 12, Ayazakhtarma; 13, Nardaran-akhtarma; 14, Garabujag; 15, Shekikhan; 16, Jairli; 17, Gizmey-dan (out of figure). The histogram plots the number of eruptions per year (after Aliyev et al., 2009); the red column refers to 2001. 
Figure 9. (a-f) Normal stress changes $\left(\Delta \sigma_{\mathrm{n}}\right.$; bar, unclamping positive) computed for different orientations of vertical receiver mud dikes (black bar, $\mathrm{N} 30^{\circ} \mathrm{E}, \mathrm{N} 80^{\circ} \mathrm{E}, \mathrm{N} 110^{\circ} \mathrm{E}$ ) imparted by the two main earthquakes of 25 November 2000; the considered focal mechanism solutions are those proposed by Jackson et al. (2002) (Table S9). The fault (surface projection in green) is $\sim 16 \mathrm{~km}$ and $\sim 14 \mathrm{~km}$ long, with $\sim 0.43 \mathrm{~m}$ and $\sim 0.36 \mathrm{~m}$ of tapered normal slip for the $\mathrm{Mw}=6.2$ and $\mathrm{Mw}=6.1$ earthquakes, respectively. Stress is sampled at $1 \mathrm{~km}$ depth. The mud volcanoes that erupted in the period December 2000-December 2001 are reported. Only the mud volcanoes with feeder dikes oriented similarly to the computed direction are shown in each panel. Identification numbers of mud volcanoes (see Table S8) are the same as those in the caption of Figure 8. (g) Satellite image showing the crater and the collapse normal faults (red lines) topping the elongated Lokbatan mud volcano (no. 10 in Fig. 8 and Table S8). The white dashed line outlines the base of the volcanic edifice. The feeder dike is assumed to align parallel to the long axis of the volcano. (h) Satellite image showing the aligned vents at Gotur (no. 4 in Fig. 8 and Table S8). Satellite images are extracted from Google Earth®.

Figure 10. (a) Context map of Salton Sea mud volcanoes (red circle) showing major regional faults (red solid lines). Black solid lines within the Salton Sea (blue) indicate faults identified in seismic reflection profiles, digitized from Brothers et al. (2009), Fig. 1a. The red dashed lines indicate local faults (Schroeder, 1976; Lynch and Hudnut 2008) along which gas escapes and springs tend to lie (Lynch and Hudnut, 2008). We show receiver fault orientations in (b), marked A and B, parallel to the normal faults within the Salton Sea and to the San Andreas Fault, respectively. (c) The Salton Sea, California mud volcanoes. Hudson Ranch II geothermal plant in the background began operations after the observations considered in this paper (photo 13 February 2012). 
Figure 11. (a) Normal stress changes $\left(\Delta \sigma_{\mathrm{n}}\right.$; bar, unclamping positive) produced by various historical triggering earthquakes along the Pede-Apennine margin of the Northern Apennines. Location and macroseismic magnitude of historical earthquakes are from Rovida et al. (2011) and CPTI Working Group (2004). The fault models are based on the seismotectonic map of Regione Emilia-Romagna (Boccaletti et al., 2004) (see text and Table S12). Stress changes imparted by these earthquakes are computed for a vertical $\mathrm{N} 15^{\circ}$ E-trending dike (black bar), which is supposedly controlling the Montegibbio mud volcano. Stress is sampled at $1 \mathrm{~km}$ depth. The Pede-Apennine thrust (red) and buried thrusts (violet) are indicated.

Figure 12. Summary of all earthquake-triggered eruptions discussed in the text and listed in Tables S1S5 and S8-S12 (modified from Rudolph and Manga, 2012). We use filled symbols to denote short-term triggering and unfilled symbols to denote long-term or delayed triggering. The black diagonal lines are contours of constant seismic energy density, with labels giving the corresponding value in $\mathrm{J} / \mathrm{m}^{3}$, based on the model of Wang (2007). The red diagonal line is one subsurface rupture length, calculated according to the empirical relationship from Wells and Coppersmith (1994) for all fault types. In addition to the triggered eruptions, we show for comparison the Yogyakarta earthquake and LUSI, indicated by the green star. 

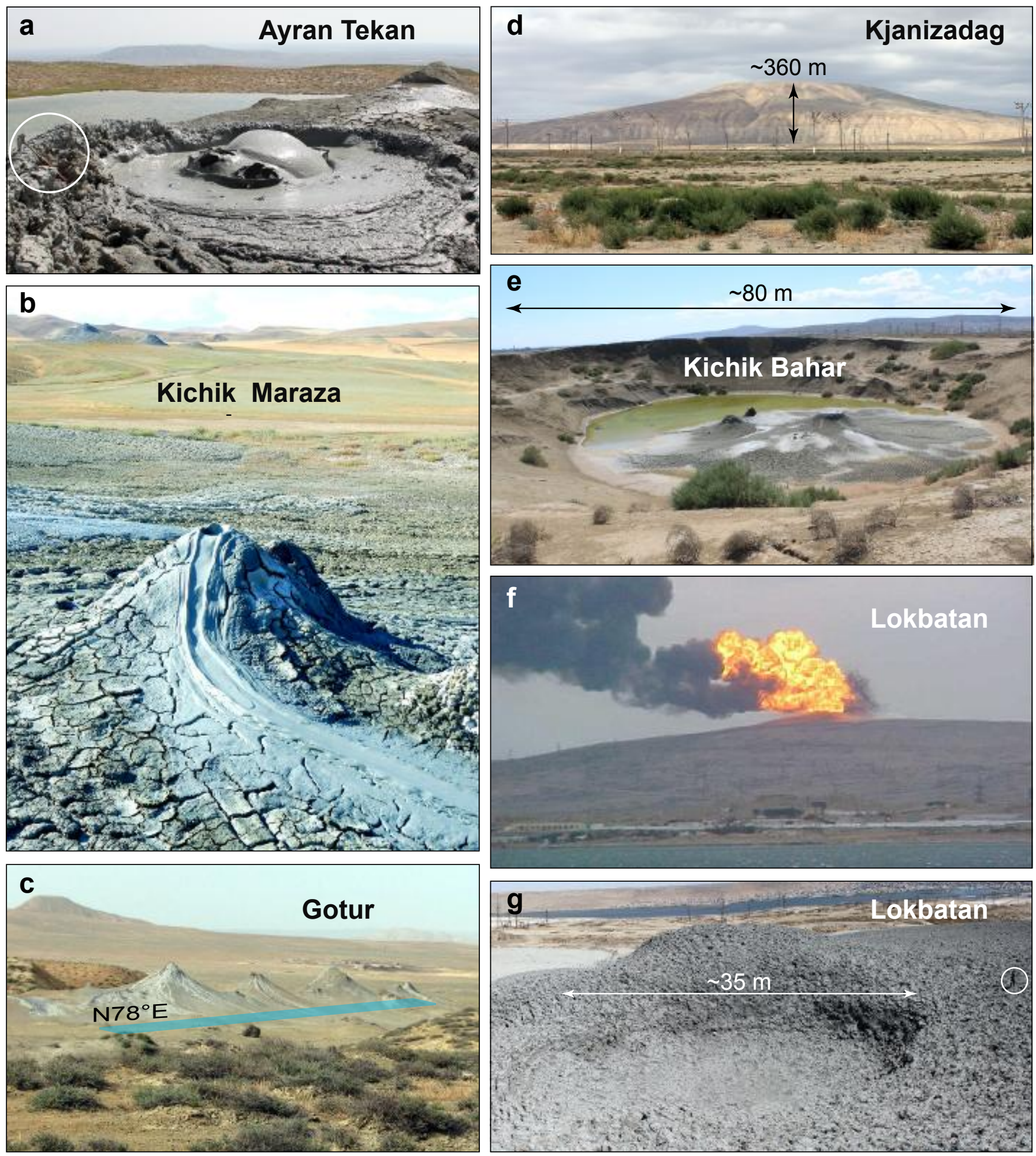

Figure 1. Characteristics of mud volcano features from Azerbaijan. (a) Large gas bubble typically popping up a crater atop a gryphon at Ayran Tekan mud volcano; hammer (circled) for scale (N39.99389 E49.30889; photo 23 May 2010). (b) Gryphon emitting a fresh mud flow in the Kichik-Maraza mud volcano field (N40.51028 E49.03194; photo 22 June 2013). (c) Alignment of mud cones mud cones and gryphons at Gotur (extracted from Google Earth ${ }^{\circ}$, http://earth.google.it/download-earth.html). (d) Lateral view of the large Kjanizadag mud volcano edifice (N40.14083 E49.38222; photo 21 June 2013). (e) Small caldera topping the gentle-sided Kichik Bahar mud volcano (N39.99805 E49.45527; photo 25 May 2010). (f) Flaming eruption at the Lokbatan mud volcano on 25 October 2001; photo by Phil Hardy — from BBC NEWS 29th October 2001, Clare Doyle in Baku. According to Mukhtarov et al. (2003), this violent explosive eruption was characterized by an initial flame approximately 300 $\mathrm{m}$ tall and $100 \mathrm{~m}$ across. (g) Lateral view of the summit crater of Lokbatan (N40.30444 E49.70916; photo 27 June 2014); person (circled) for scale. 

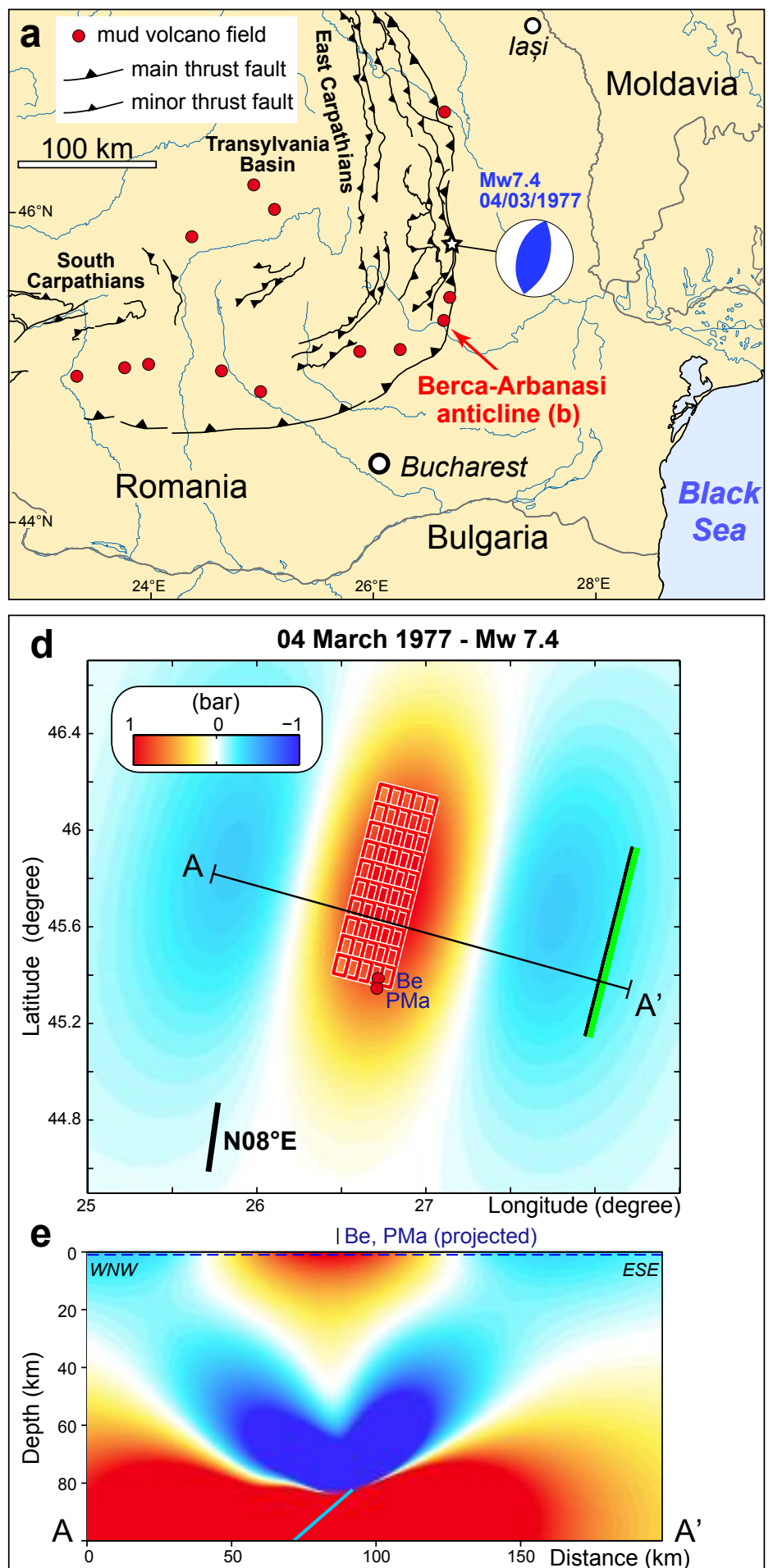
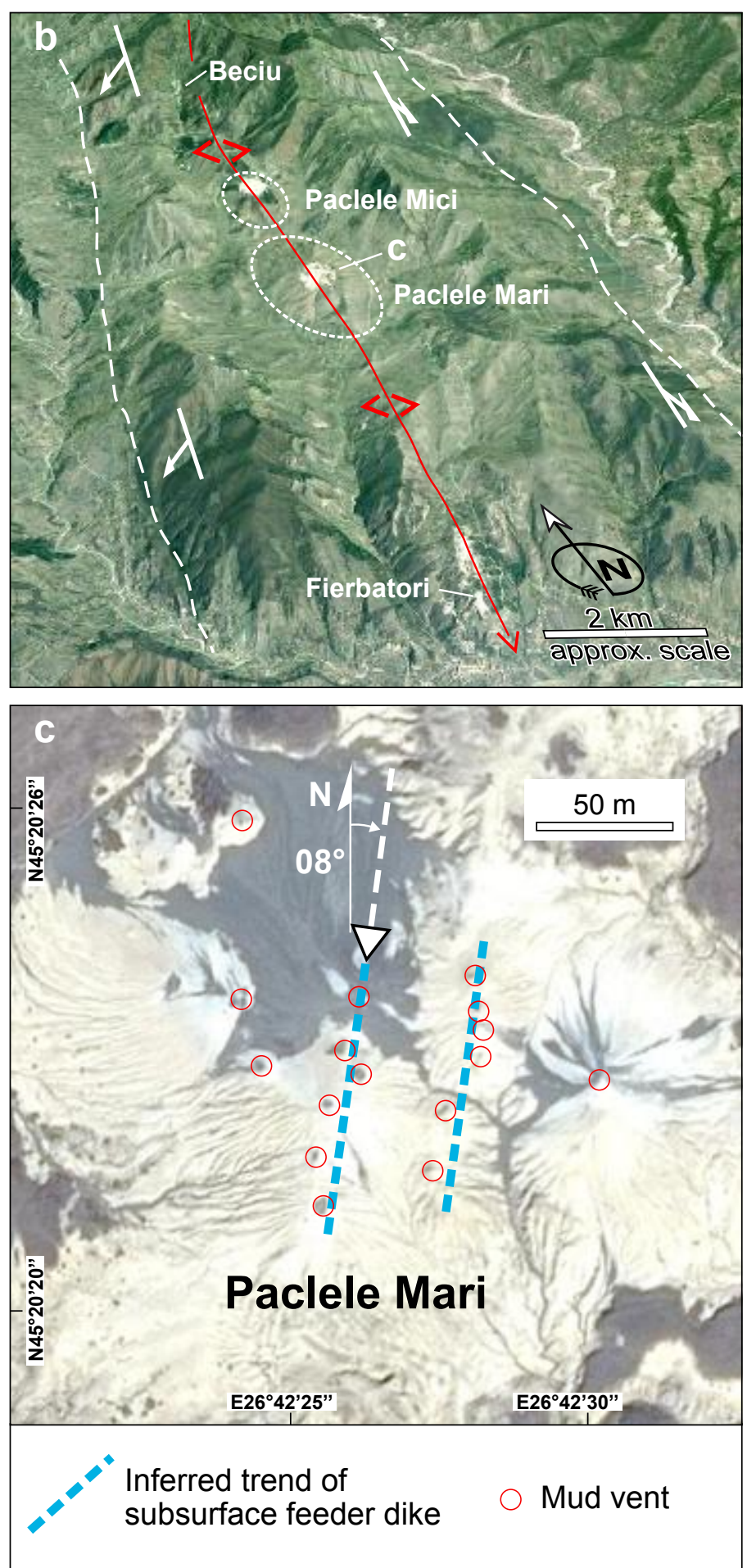

Figure 2. (a) Tectonic sketch map of the Carpathian fold-and-thrust belt. Epicenter and focal mechanism of the Mw7.4 04 March 1977 Vrangea earthquake are reported form Oncescu and Bonjer (1997). (b) Oblique view of the 20 km-long Berca-Arbanasi fold anticline, which exposes four mud volcano fields along its axis (from North to South), Beciu, Paclele Mici, Paclele Mari and Fierbatori. (c) Satellite image showing the aligned vents within the area of active seepage atop the Paclele Mari mud volcano edifice. (b) and (c) are extracted from Google Earth ${ }^{\circledR}$, http://earth.google.it/download-earth.html. (d) Normal stress changes ( $\Delta \sigma n$; bar, unclamping positive) imparted by the 1977 Vrancea earthquake. Berciu (Be) and Paclele Mari (PMa) mud volcanoes are indicated. Stresses are computed on $\mathrm{N} 08^{\circ} \mathrm{E}$ orientated vertical receiver dikes (black bar); the example reports the result obtained from the source model proposed by Oncescu and Bonjer (1997) and Ganas et al. (2010) (Table S1). The model also considers a 50-patch source. (e) Cross section of normal stress changes. The blue dashed line indicates the horizontal section (1 km depth) of stress change distribution shown in panel (d). 

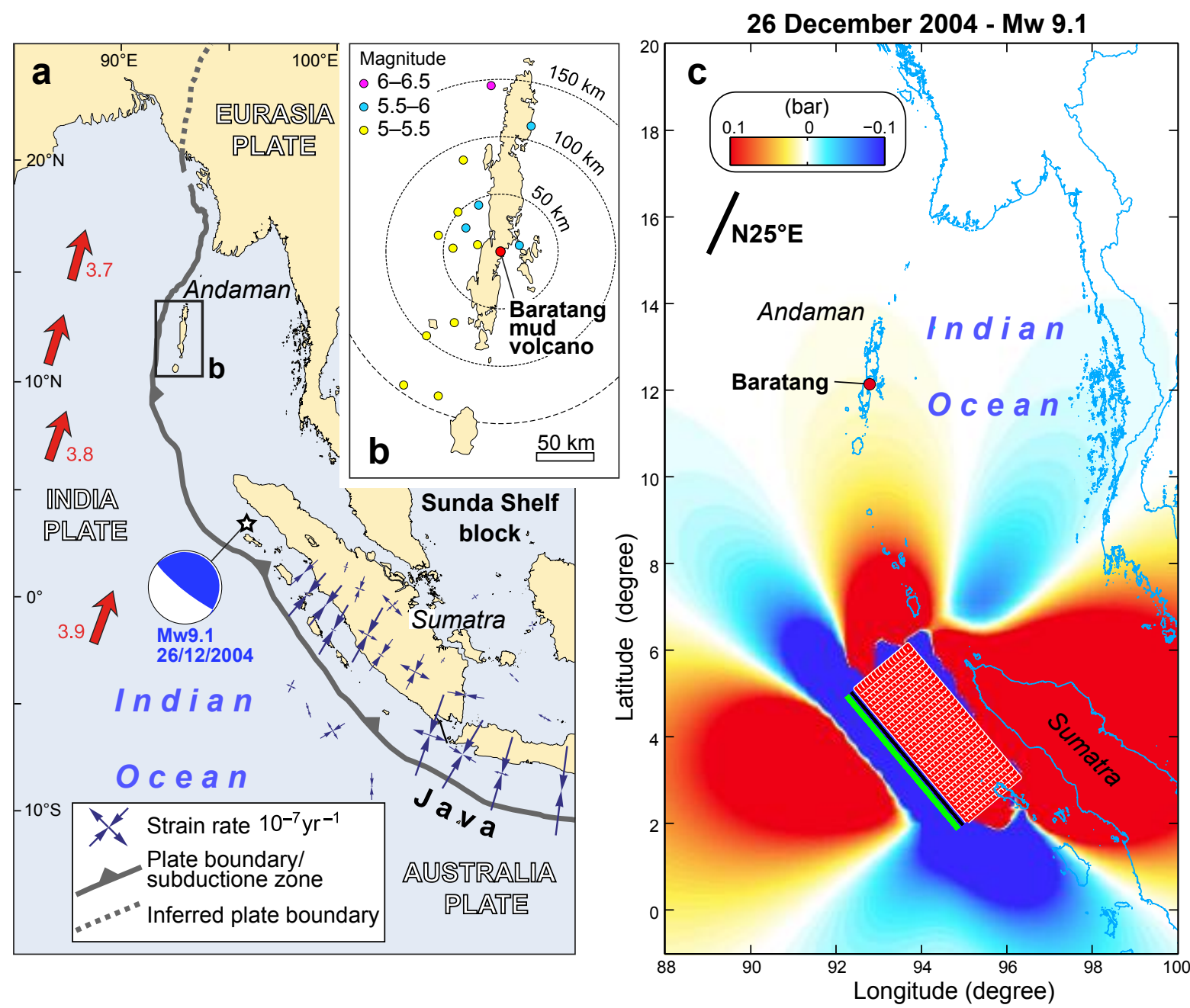

Figure 3. (a) Tectonic sketch map of the western Indonesian archipelago. The red arrows indicate 1 plate velocities of India relative to the Sunda Shelf block (Subarya et al., 2006). Dark blue arrows 2 indicate computed (contraction/extension) principal surface strain rates (Bock et al., 2003). (b) 3 Detail of Andaman Islands showing earthquakes with $M \geq 5$ of 26 and 27 December 2004, and 4 distance from the Baratang mud volcano that erupted after the Mw9.1 earthquake. Focal mechanism 5 solution of 26 December 2004 earthquake and seismicity around the Andaman Islands are from 6 USGS (http://earthquake.usgs.gov). (c) Normal stress changes $(\Delta \sigma \mathrm{n}$; bar, unclamping positive) 7 produced by the Great Sumatra earthquake of 26 December 2004. Stress changes are computed for 8 a vertical $\mathrm{N} 25^{\circ} \mathrm{E}$-trending dike (black bar), which is supposedly controlling the mud volcano in 9 Baratang (Andaman-Nicobar Islands) that erupted immediately after the earthquake. The fault 10 model considers a 450-patch source model (downloaded at 11 http://www.seismo.ethz.ch/static/srcmod/Homepage.html; Ammon et al., 2005), with Mw 99, fault 12 strike $=320^{\circ} \mathrm{E}, \operatorname{dip}=15^{\circ}$, length $=450 \mathrm{~km}$, width $=180 \mathrm{~km}, \mathrm{rake}=91.7$. Stress is sampled at $1 \mathrm{~km}$ depth. 13 

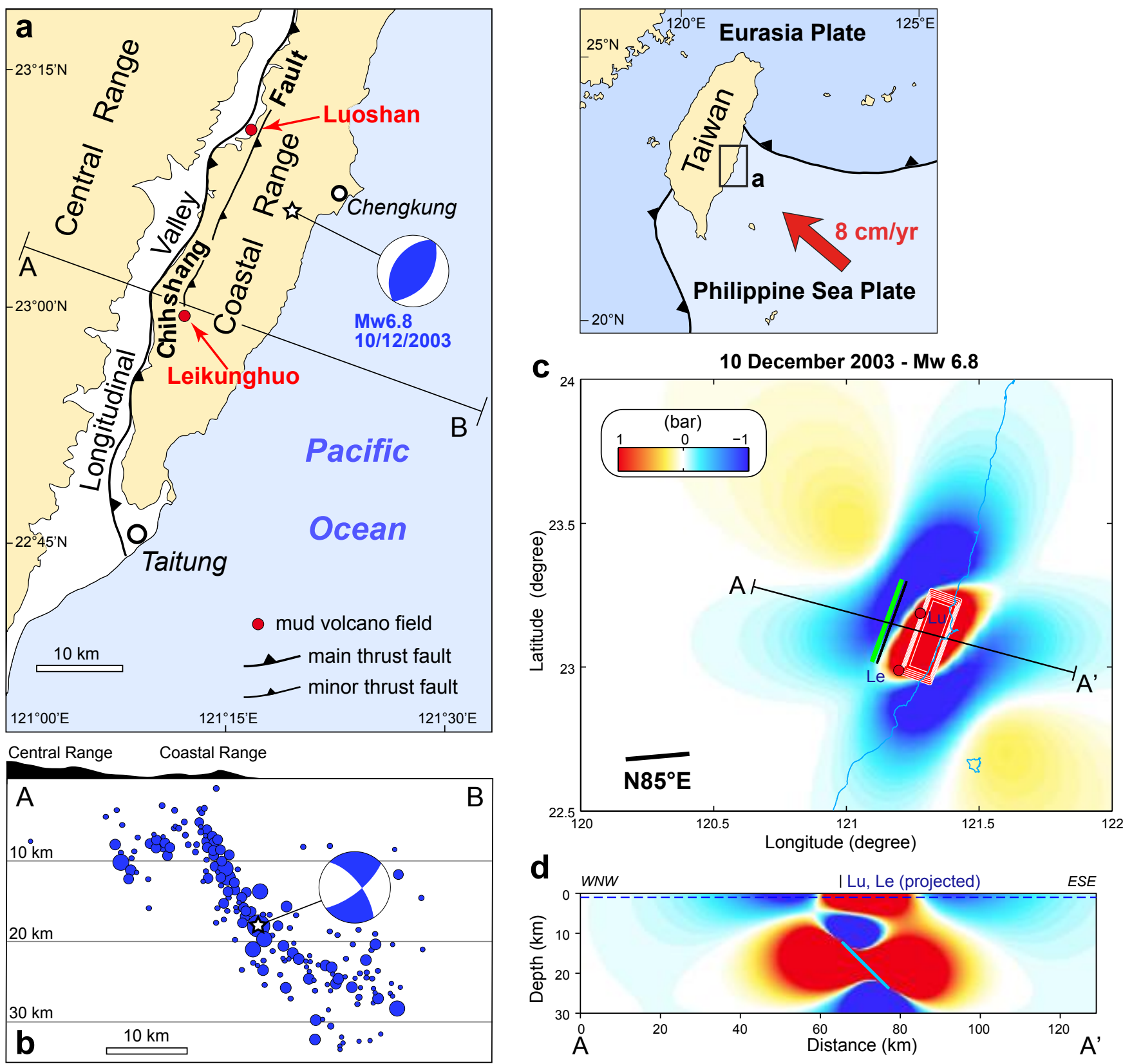

Figure 4. (a) Tectonic sketch map of southeastern Taiwan. Epicenter and focal mechanism of the Mw6.8 10 December 2003 Chengkung earthquake are reported form Wu et al. (2006). (b) Hypocenters of the 2003 Chengkung earthquake sequence delineating the listric geometry of the causative Chihshang Fault (redrawn from Wu et al., 2006). (c) Normal stress changes ( $\Delta \sigma \mathrm{n}$; bar, unclamping positive) imparted by the 2003 Chengkung earthquake. Stresses are computed on $\mathrm{N} 85^{\circ} \mathrm{E}$ orientated vertical receiver dikes (black bar); the example reports the result obtained from the source model proposed by Wu et al. (2006) (Table S3). Luoshan (Lu) and Leikunghuo (Le) mud volcanoes are indicated. (d) Cross section showing normal stress changes. The blue dashed line indicates the horizontal section (1 km depth) of stress change distribution shown in panel (c). 

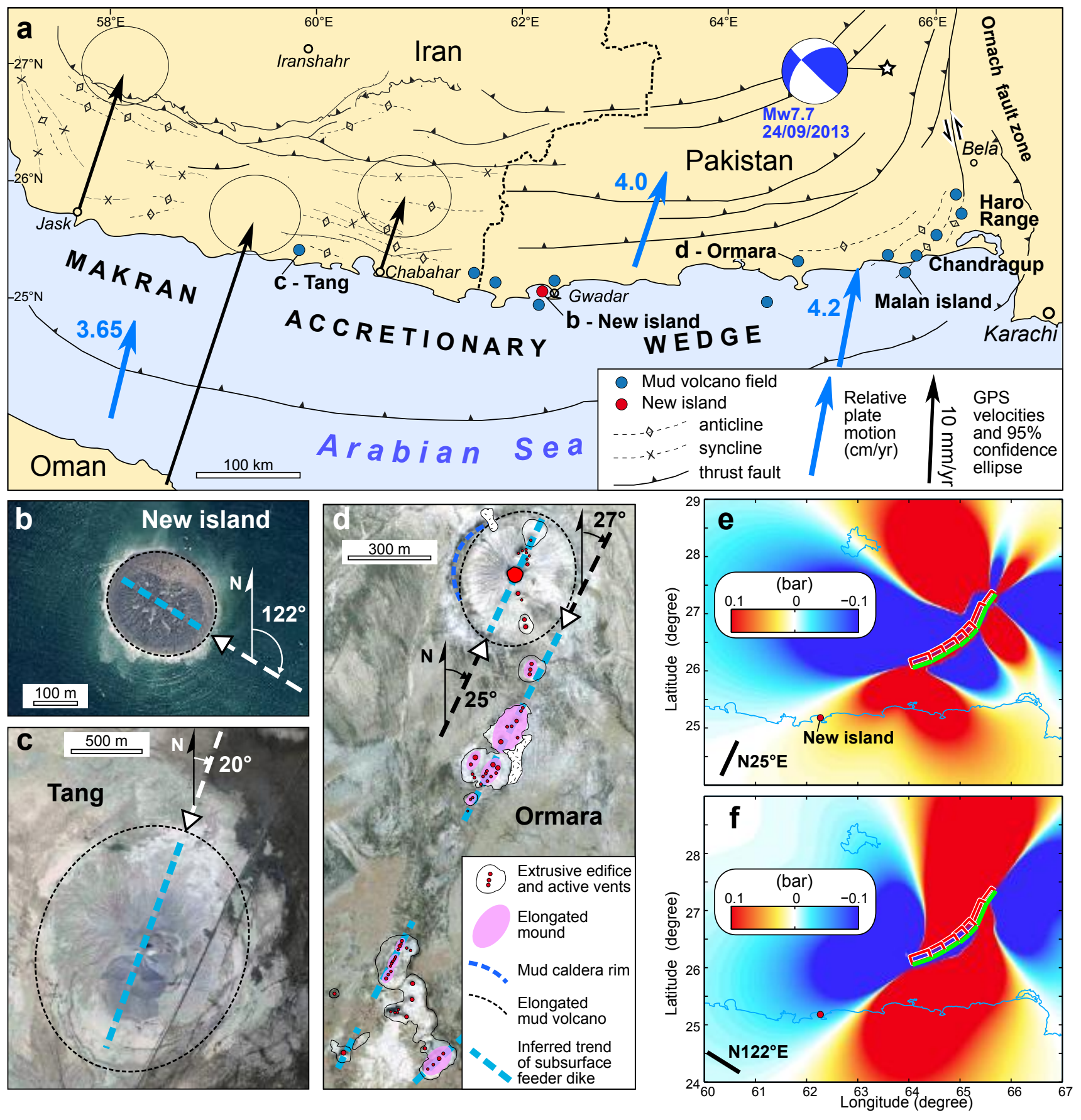

Figure 5. (a) Tectonic sketch map of the Makran accretionary wedge of south-eastern Iran and southern Pakistan (compiled from Snead, 1964; Kukowski et al., 2001; Schlüter et al., 2002; Burg et al., 2008). The black arrows show GPS horizontal velocities in a Eurasia-fixed reference frame (after Nilforoushan et al., 2003). The blue arrows indicate relative plate motion and convergence velocities (DeMets et al.,1990; Kukowski et al., 2001). Focal mechanism solution of 24 September 2013 earthquake from USGS (http://earthquake.usgs.gov). (b) Satellite image (26 September 2013) of the new island offshore Gwadar. Satellite images (extracted from Google Earth ${ }^{\circledR}$ ) showing the (c) elongated Tang mud volcano, and (d) vent alignments and an elongated volcano in the Ormara field. (e, f) Normal stress changes (Aбn; bar, unclamping positive) produced by the $\mathrm{Mw}=7.7$ Balochistan earthquake of 24 September 2013. Stress changes are computed for different orientations of possible vertical receiver dikes (black bar) that are inferred to have controlled the mud volcano system that spawned the new island (red circle) that appeared offshore Gwadar shortly after the earthquake (see Table S4). The fault model considers a 7-patch source (after Avouac et al., 2014), as well as a uniform rake=6. Stress is sampled at $1 \mathrm{~km}$ depth. 


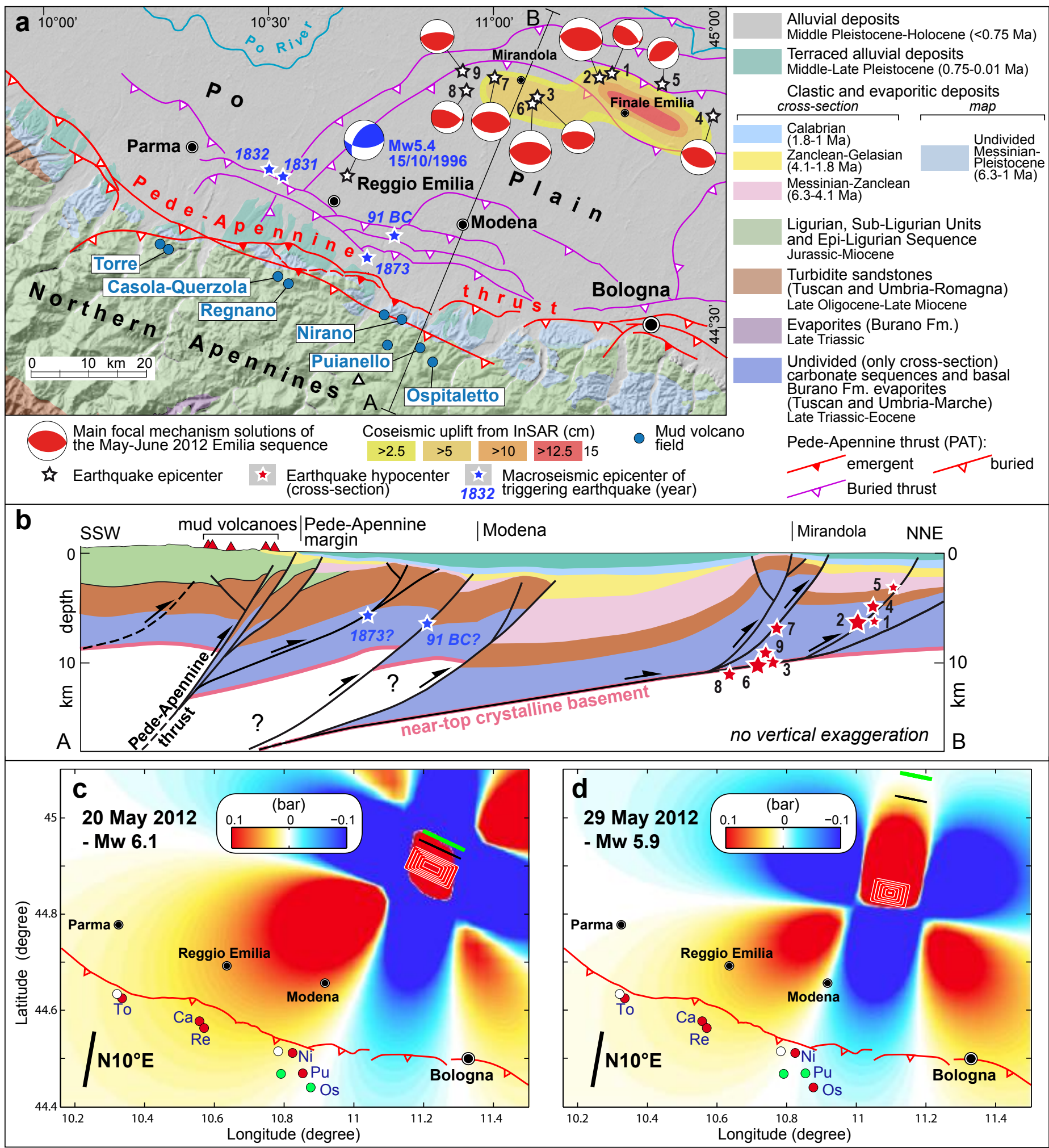

Figure 6. (a) Geological setting of the external Northern Apennines (northern Italy). Focal mechanism solutions of main earthquakes of the May-June 2012 Emilia seismic sequence are reported (from INGV, TDMT; http://cnt.rm.ingv.it/tdmt.html); numbers indicate earthquake chronology: 1, M=4.3 (19 May 2012); 2, M=6.1 (20 May 2012); 3, M=4.9 (20 May 2012); 4, M=5.1 (20 May 2012); 5, M=4.5 (20 May 2012); 6, M=5.9 (29 May 2012); 7, M=5.3 (29 May 2012); 8, M=4.9 (29 May 2012); 9, M=5.1 (03 June 2012). The modeled coseismic deformation field detected through InSAR analysis is reported (after Bignami et al., 2012). (b) Schematic crustal-scale cross section through the Northern Apennines and Po Plain. Hypocenters of main 2012 earthquakes (after Saraò and Peruzza, 2012) are projected onto the NNE-SSW striking profile. Computed changes of normal stress (Aбn; bar, unclamping positive) produced by the $\mathrm{Mw}=6.120$ May and $\mathrm{Mw}=5.929$ May 2012 earthquakes (panels c and d, respectively). Normal stress changes are computed on average $\mathrm{N} 10^{\circ} \mathrm{E}$-oriented vertical dikes (black bar), which are inferred to be the dominant feeder system of mud volcanoes (e.g., Bonini, 2012). Fault parameters (Table S6) are taken from the inversion of the SAR dataset (Bignami et al., 2012), and the empirical scaling of Wells and Coppersmith (1994). The fault (surface projection in green) is $\sim 12 \mathrm{~km}$ and $\sim 9 \mathrm{~km}$ long, with $\sim 0.56 \mathrm{~m}$ and $\sim 0.48 \mathrm{~m}$ of tapered reverse slip for the $\mathrm{Mw}=6.1$ and $\mathrm{Mw}=5.9$ earthquakes, respectively. Stress is sampled at $1 \mathrm{~km}$ depth. The thick red line indicates the Pede-Apennine thrust. The red circles indicate the mud volcanoes that increased their activity within few days after the seismic events, in green those that did not show apparent response, and in white those that have not been inspected. Mud volcanoes: To, Torre; Ca, Casola-Querzola; Re, Regnano; Ni, Nirano; Pu, Puianello; Os, Ospitaletto. 

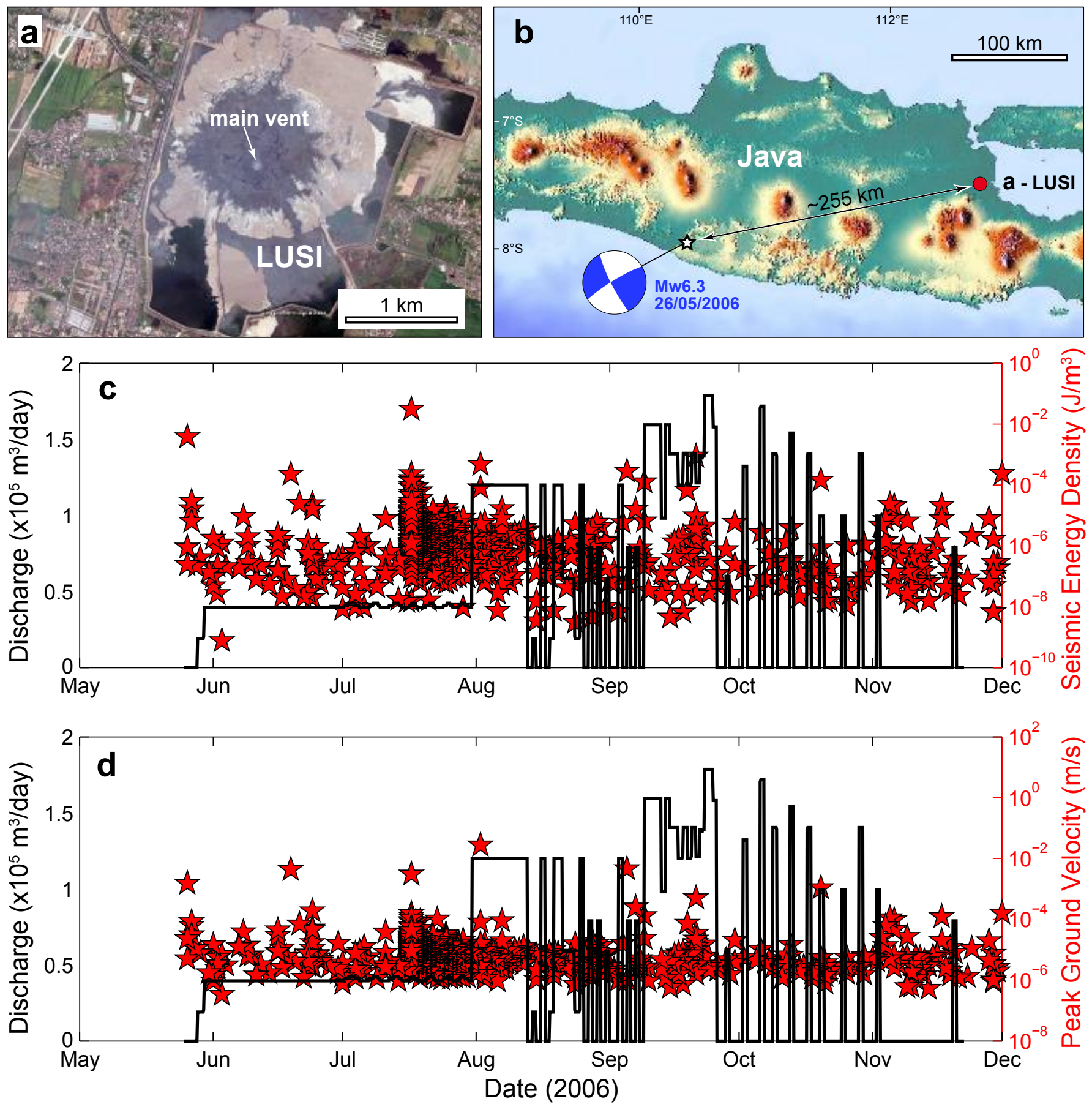

Figure 7. (a) Satellite image (August 2012) showing the LUSI mud volcano in east Java (S7.52718 E112.71166). Image extracted from Google Earth ${ }^{\circledR}$. (b) Location of LUSI and the Mw 6.3 Yogyakarta earthquake that hit central Java on 26 May 2006. Focal mechanism solution from USGS (http://earthquake.usgs.gov). (c) Discharge at LUSI (black line, left vertical axis), digitized from Figure 5 in Mazzini et al. (2007), and earthquakes (red stars) from the USGS catalog within $1500 \mathrm{~km}$ of LUSI. The vertical position of each seismic event corresponds to the calculated seismic energy density at LUSI (right vertical axis - note log scale). (d) Same as (c) except that we position each seismic event vertically based on the calculated peak ground velocity using the empirical attenuation relationship for East Java from Davies et al. (2008). 


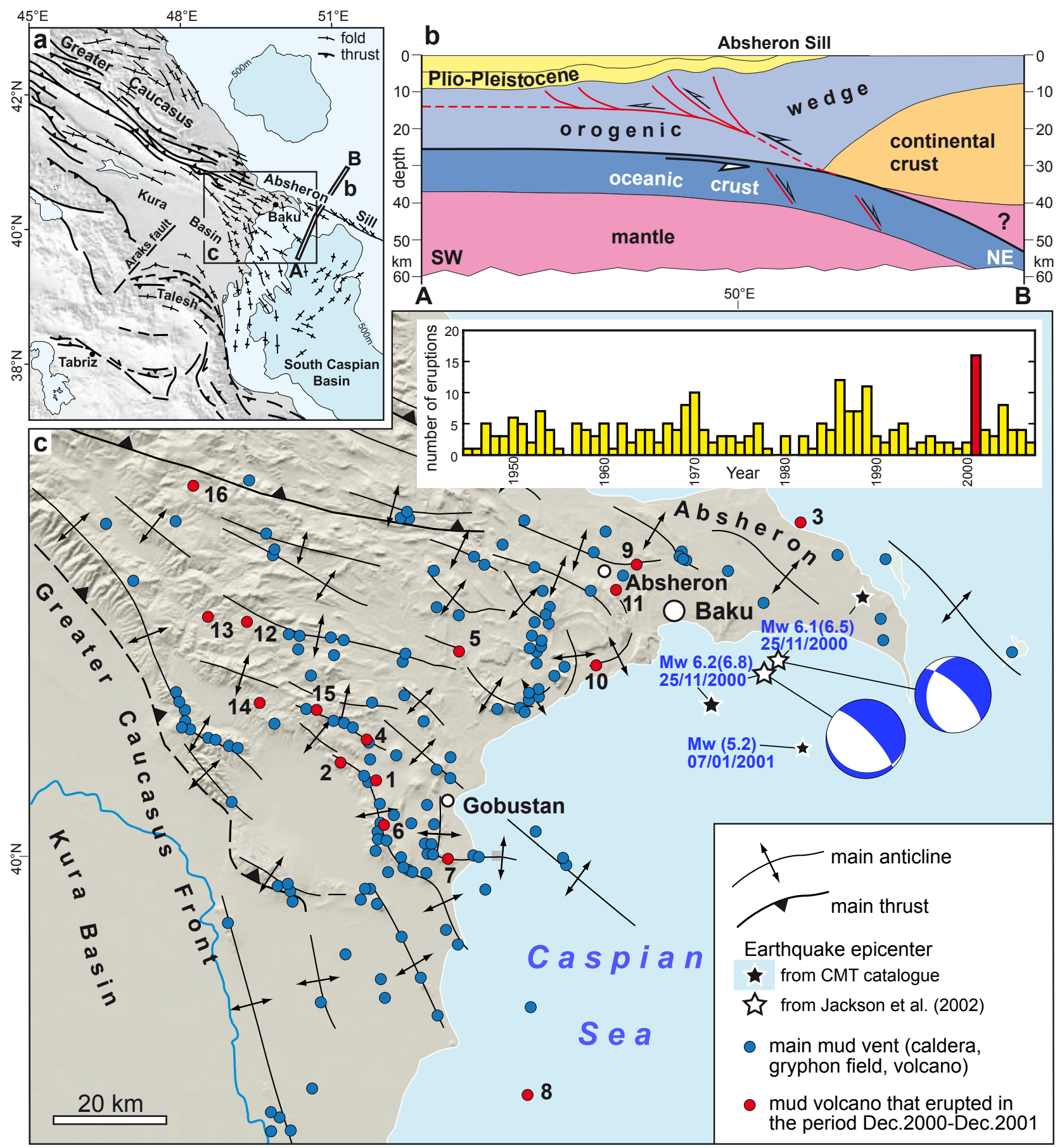

Figure 8. (a) Schematic structural map of the Greater Caucasus-eastern Caspian Basin (modified after Jackson et al., 2002). (b) Regional cross section through the Absheron Sill and the South Caspian Basin (modified from Knapp et al., 2000). (c) Main structures and mud volcano fields between the Greater Caucasus front and Absheron Peninsula in Azerbaijan. Earthquake epicenters and magnitude (Mw) are from Jackson et al. (2002) and global Centroid Moment Tensor solutions catalog (http://www.globalcmt.org/); the magnitude $\mathrm{Mw}$ in parenthesis refers to Centroid Moment Tensor solutions. The NE-dipping normal faults in the oceanic crust (b) are hinted to be the causative faults of the 2000 seismic sequence. Mud volcanoes that erupted after the 25 November 2000 earthquakes (period Dec.2000-Dec. 2001, in roughly chronologic order) are (Mellors et al., 2007; Aliyev et al., 2009) (Table S8): 1, Akhtimer (Agtirma); 2, Durandag; 3, Buzovna-sopkasi (Pilpila-Buzovna); 4, Gotur; 5, Chapylmish; 6, Solakhai; 7, Dashgil; 8, Chigil-deniz; 9, Keyreki; 10, Lokbatan; 11, Bozdag-Gekmaly; 12, Ayazakhtarma; 13, Nardaranakhtarma; 14, Garabujag; 15, Shekikhan; 16, Jairli; 17, Gizmey-dan (out of figure). The histogram plots the number of eruptions per year (after Aliyev et al., 2009); the red column refers to 2001. 
25 November 2000 - Mw 6.2 Earthquake 1
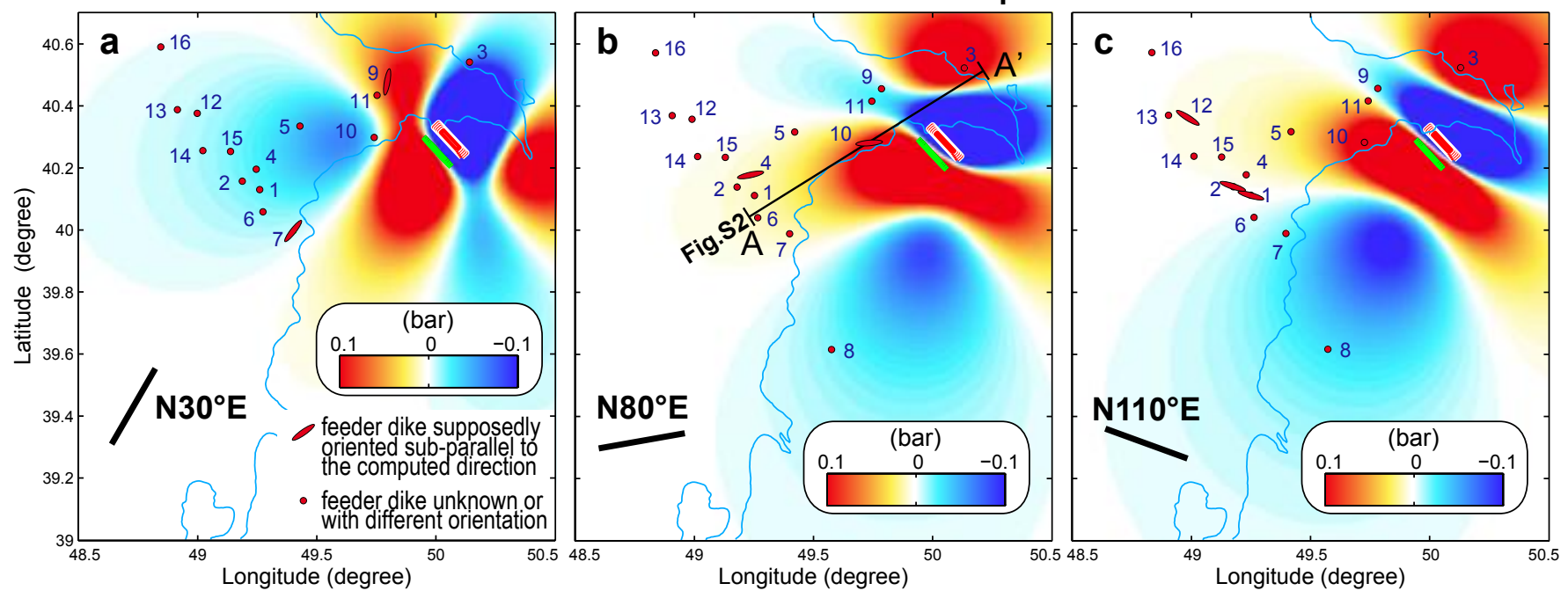

25 November 2000 - Mw 6.1 Earthquake 2
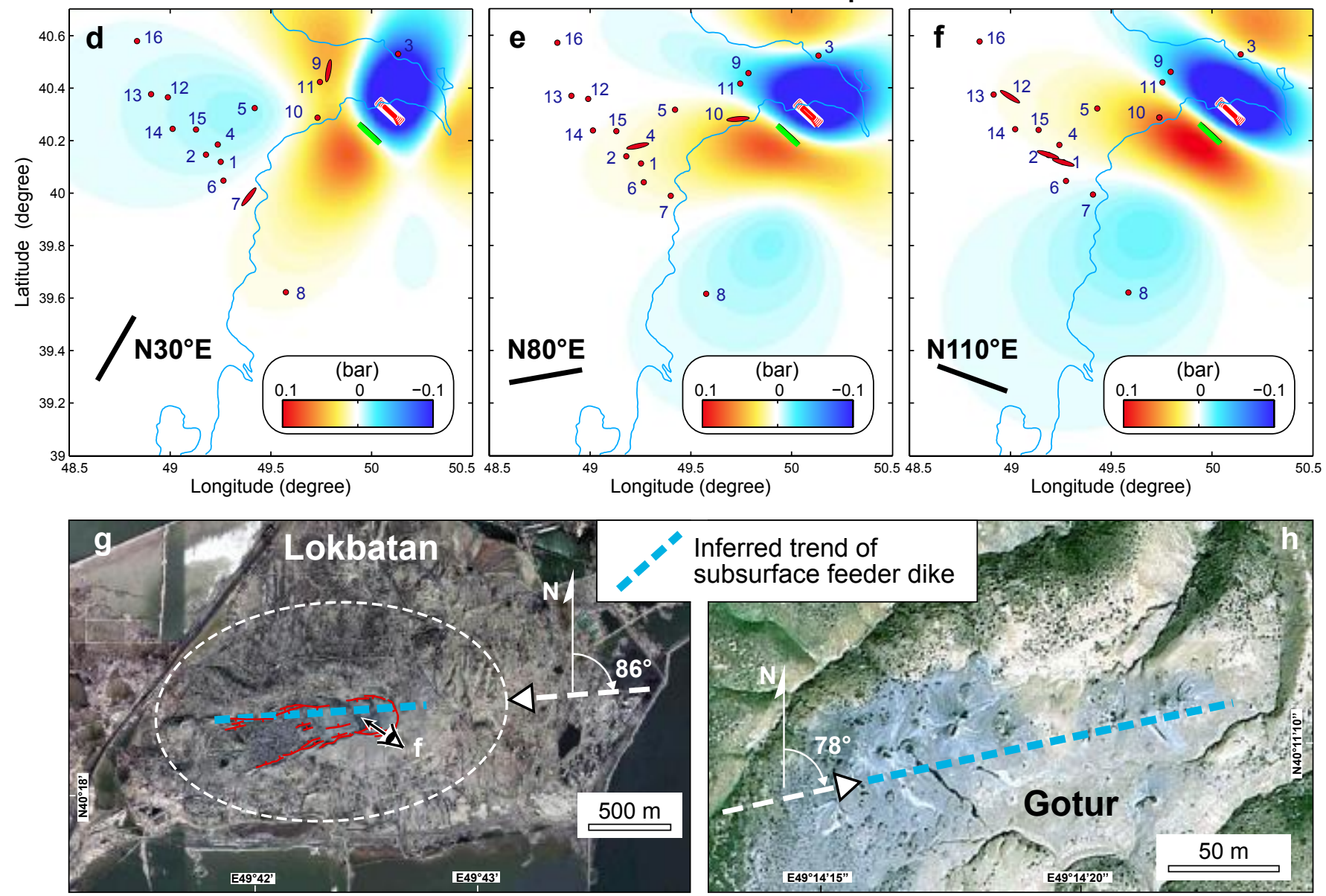

Figure 9. (a-f) Normal stress changes (Aøn; bar, unclamping positive) computed for different orientations of vertical receiver mud dikes (black bar, $\mathrm{N} 30^{\circ} \mathrm{E}, \mathrm{N} 80^{\circ} \mathrm{E}, \mathrm{N} 110^{\circ} \mathrm{E}$ ) imparted by the two main earthquakes of 25 November 2000 ; the considered focal mechanism solutions are those proposed by Jackson et al. (2002) (Table S9). The fault (surface projection in green) is $\sim 16 \mathrm{~km}$ and $\sim 14 \mathrm{~km}$ long, with $\sim 0.43 \mathrm{~m}$ and $\sim 0.36 \mathrm{~m}$ of tapered normal slip for the $\mathrm{Mw}=6.2$ and $\mathrm{Mw}=6.1$ earthquakes, respectively. Stress is sampled at $1 \mathrm{~km}$ depth. The mud volcanoes that erupted in the period December 2000-December 2001 are reported. Only the mud volcanoes with feeder dikes oriented similarly to the computed direction are shown in each panel. Identification numbers of mud volcanoes (see Table S8) are the same as those in the caption of Figure 8. (g) Satellite image showing the crater and the collapse normal faults (red lines) topping the elongated Lokbatan mud volcano (no. 10 in Fig. 8 and Table S8). The white dashed line outlines the base of the volcanic edifice. The feeder dike is assumed to align parallel to the long axis of the volcano. (h) Satellite image showing the

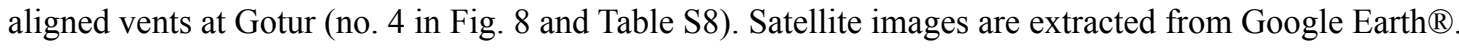



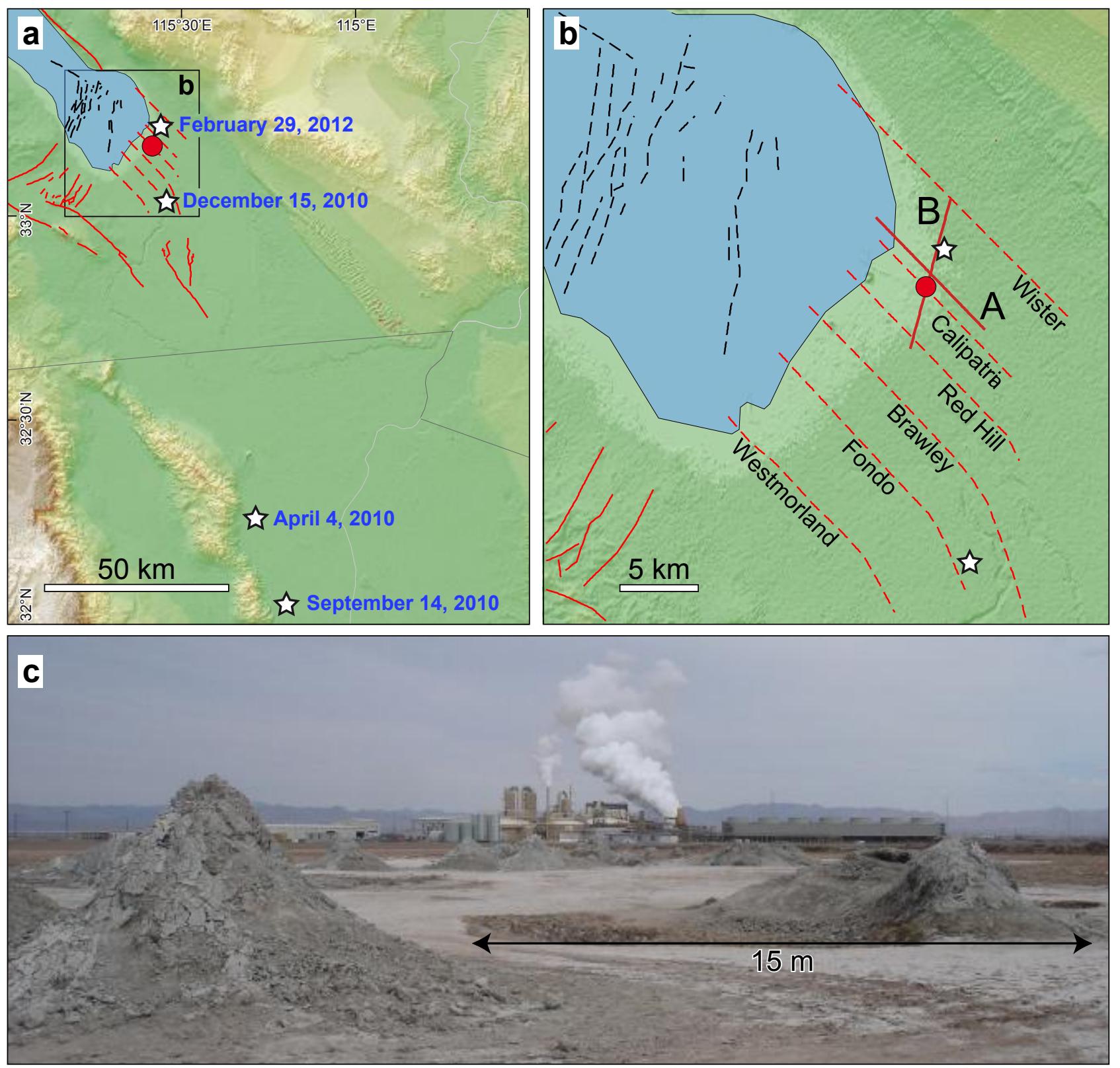

Figure 10. (a) Context map of Salton Sea mud volcanoes (red circle) showing major regional faults (red solid lines). Black solid lines within the Salton Sea (blue) indicate faults identified in seismic reflection profiles, digitized from Brothers et al. (2009), Fig. 1a. The red dashed lines indicate local faults (Schroeder, 1976; Lynch and Hudnut 2008) along which gas escapes and springs tend to lie (Lynch and Hudnut, 2008). We show receiver fault orientations in (b), marked A and B, parallel to the normal faults within the Salton Sea and to the San Andreas Fault, respectively. (c) The Salton Sea, California mud volcanoes. Hudson Ranch II geothermal plant in the background began operations after the observations considered in this paper (photo 13 February 2012). 
$91 \mathrm{BC}-\mathrm{Mw} \approx 5.7$

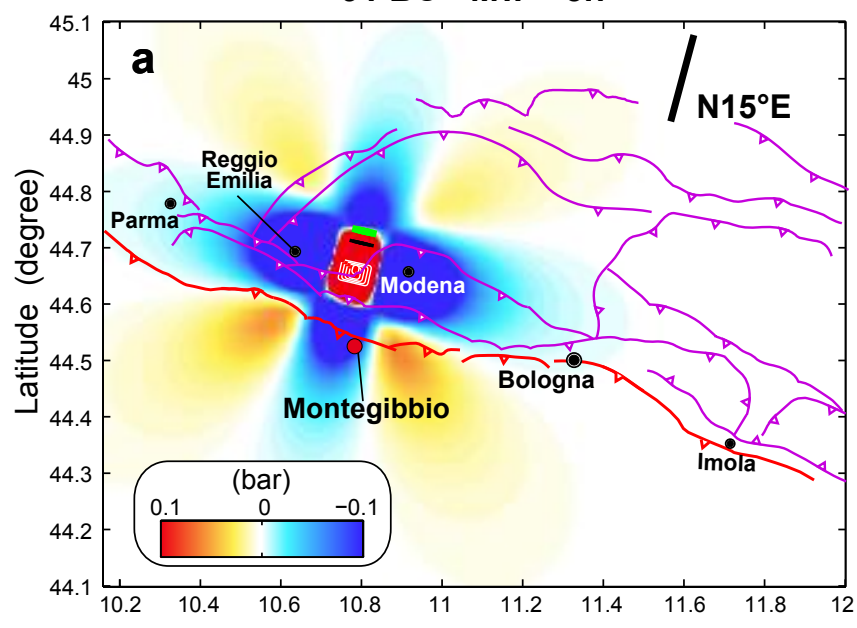

13 March $1832-$ Mw $\approx 5.5$

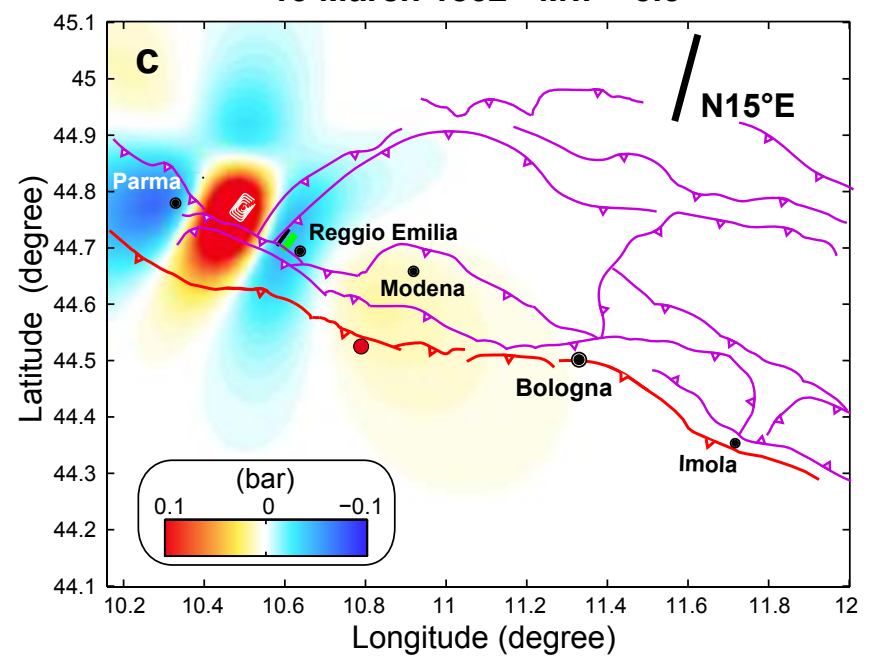

04 April $1781-M w \approx 5.9$

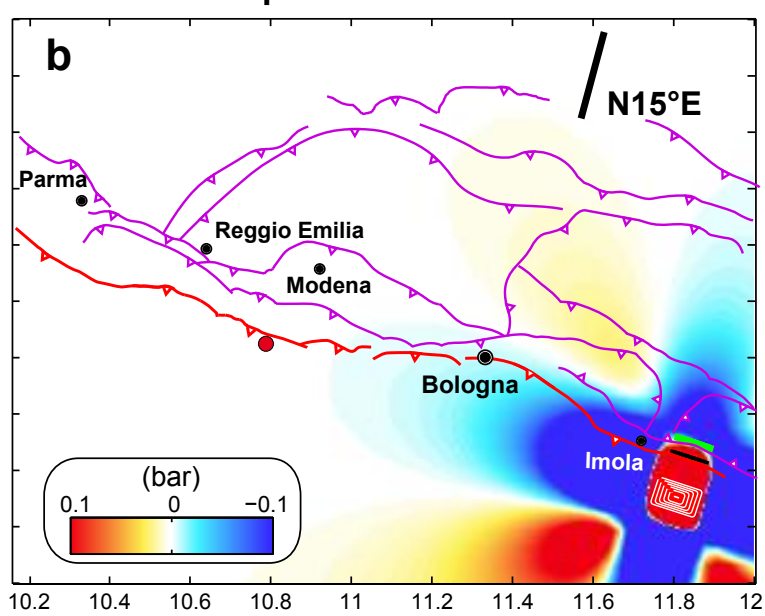

16 May $1873-M w \approx 5.1$

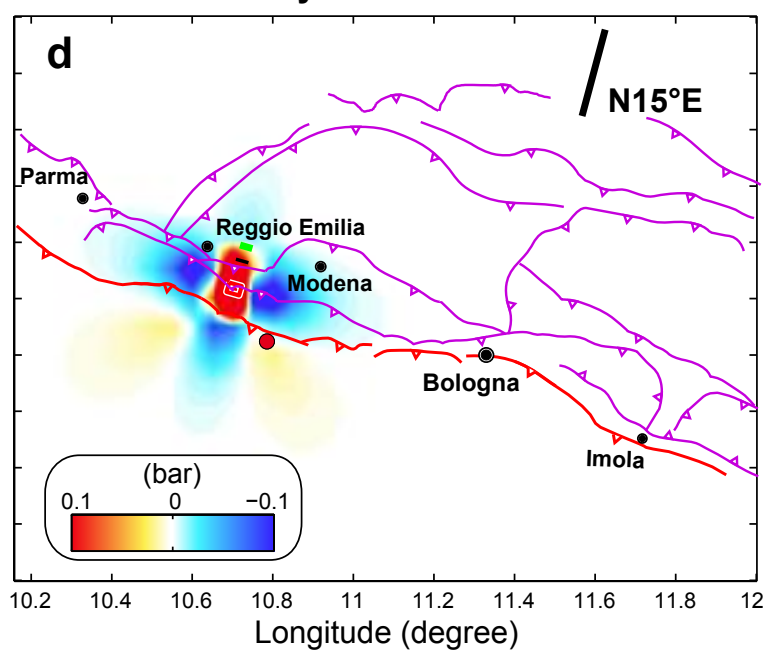

Figure 11. (a) Normal stress changes ( $\Delta \sigma n$; bar, unclamping positive) produced by various historical triggering earthquakes along the Pede-Apennine margin of the Northern Apennines. Location and macroseismic magnitude of historical earthquakes are from Rovida et al. (2011) and CPTI Working Group (2004). The fault models are based on the seismotectonic map of Regione Emilia-Romagna (Boccaletti et al., 2004) (see text and Table S12). Stress changes imparted by these earthquakes are computed for a vertical $\mathrm{N} 15^{\circ} \mathrm{E}$-trending dike (black bar), which is supposedly controlling the Montegibbio mud volcano. Stress is sampled at $1 \mathrm{~km}$ depth. The Pede-Apennine thrust (red) and buried thrusts (violet) are indicated. 


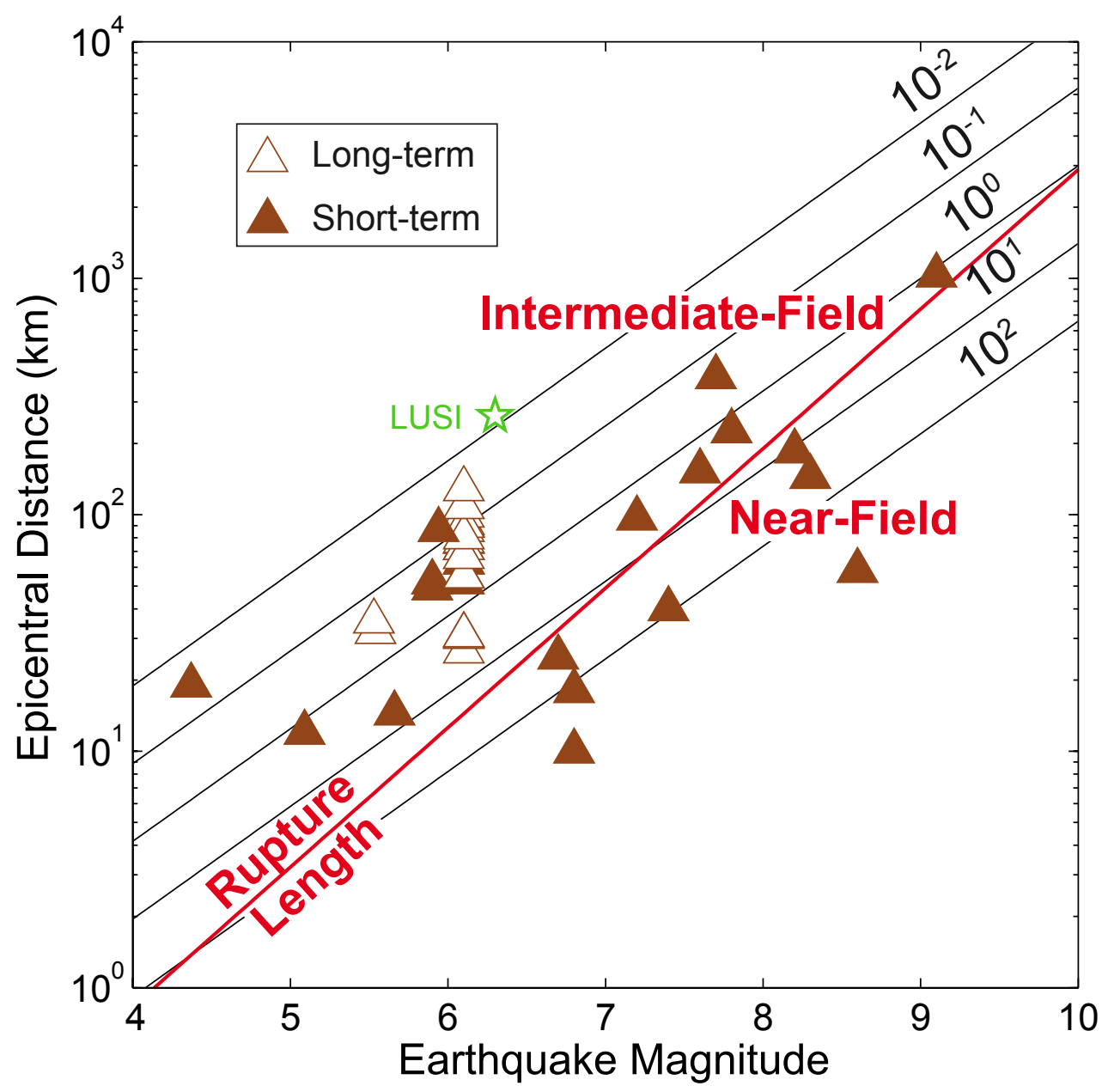

Figure 12. Summary of all earthquake-triggered eruptions discussed in the text and listed in Tables S1-S5 and S8-S12 (modified from Rudolph and Manga, 2012). We use filled symbols to denote short-term triggering and unfilled symbols to denote long-term or delayed triggering. The black diagonal lines are contours of constant seismic energy density, with labels giving the corresponding value in $\mathrm{J} / \mathrm{m} 3$, based on the model of Wang (2007). The red diagonal line is one subsurface rupture length, calculated according to the empirical relationship from Wells and Coppersmith (1994) for all fault types. In addition to the triggered eruptions, we show for comparison the Yogyakarta earthquake and LUSI, indicated by the green star. 